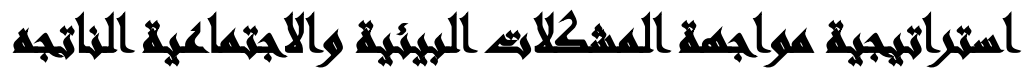

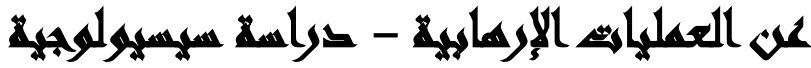

[9]

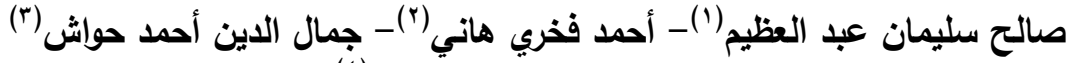

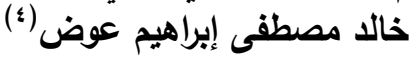

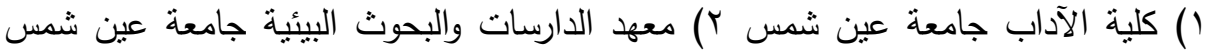

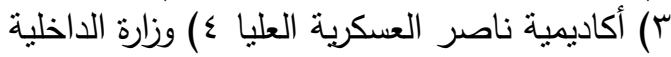

\section{المستمبت}

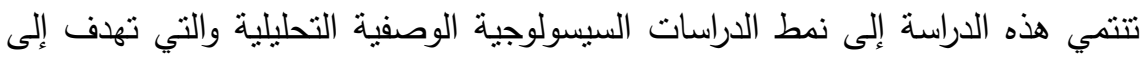

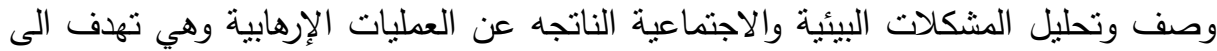

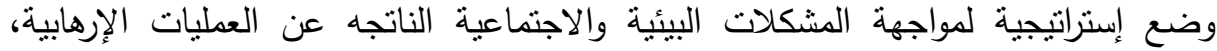

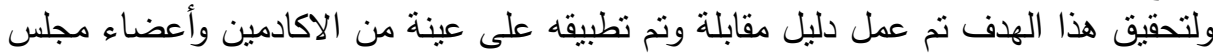

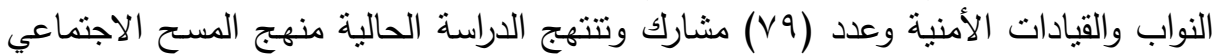

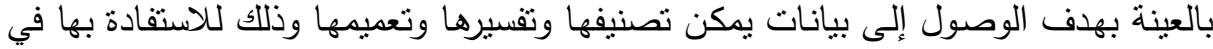

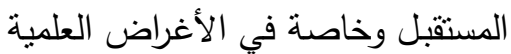

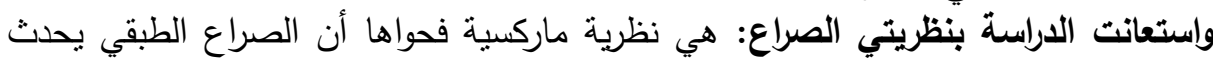

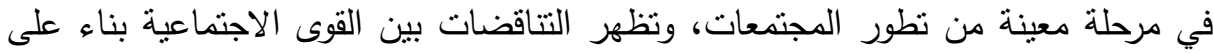

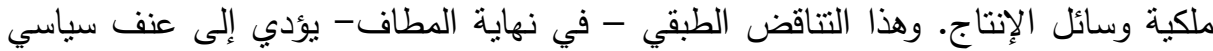

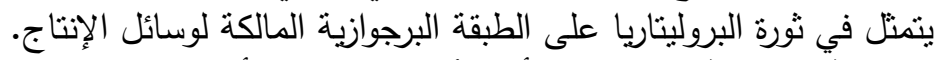

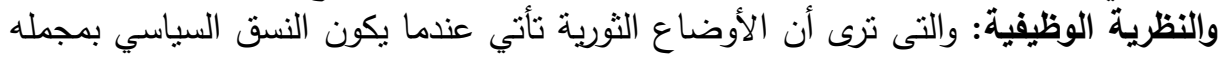

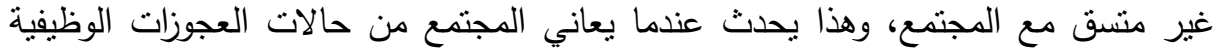

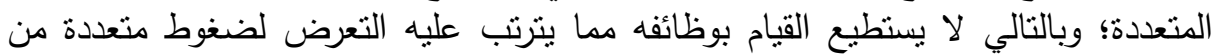

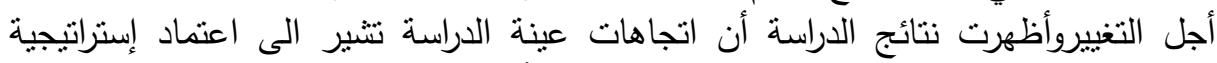

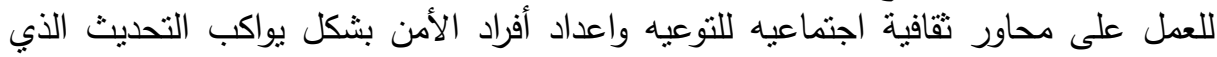
يطرأعلي الجريمة المنظمة. كما أوصت الدراسة بوضع تعريف محدد وشامل لمفهوم الإرهاب تتبناه كافة الدول والمنظمات الدولية والإقليمية. ووجوب عقد الأبحاث والدراسات عن الآثار السياسية والأمنية المترتبة على ظاهرة

الإرهاب على كافة المستويات(المحلي والإقليمي والدولي)، والعمل على التكامل فيما بينها.

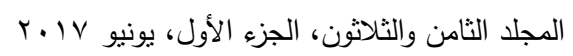


بالاضافة الى عقد الاتفاقيات الدولية الثنائية أو متعددة الأطراف حول جريمة الإرهاب، وتفعيل بنودها، وتزويد الأجهزة الأمنية بالثقنيات الحديثة اللازمة لمواجهة الإرهاب بكل الإنل صوره

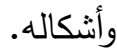

ورانشاء وتطوير الأنظمة الأمنية، بحيث تتواكب مع التطور النوعي في العطليات الإرهابية.

عقد ميثاق شرفي دولي يختص بتحديد آليات العمل الدبلوماسي بين الدول في مجال مكافحة الإرهاب، كقضايا تسليم وتسلم العناصر المطلوبة أمنياً (الإرهابيين) عدم استغلال الإل الإلين القنوات الدبلوماسية في تحقيق أهداف المنظمات الإرهابية.

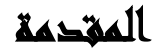

إن انتشار العمليات الارهابيه في العديد من الدول بهذه الصورة يؤكد أن هناك مشكلة تهدد المجتمع بل العالم كله، وهو الارهاب اضافة الى أنه اصبح جريمة منظمة مما زاد لهاد المشكلة تعقيدًا،، وذلك نتيجة الظروف السياسية والاقتصادية التي تمر بها معظم الدول ولاسيما الدول النامية، وهذه الظروف أدت إلى عدم قدرة الدول إلى مسايرة هذا النطور في لني

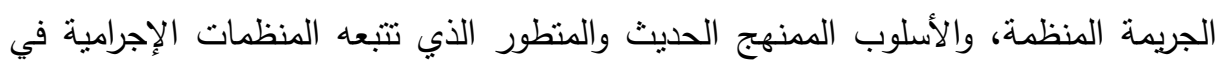
تحقيق أهدافها، كما ساهم في انتشار هذه الظاهرة عوامل أخري متفرعة، مما تطلب من لنعان العاملين تكثيف الجهود والتعاون على جميع الأصعدة، حسب الاقتضاء، من أجل تحسين

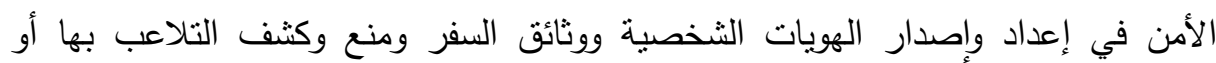
استخدامها بشكل مزور، مع التسليم في الوقت نفسه بأن الدول قد تحتاج إلى المساعدة للقيام

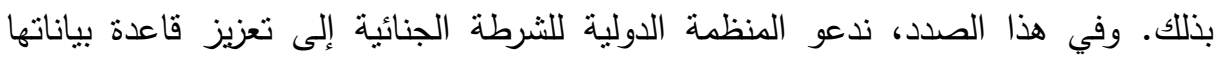
المتعلقة بوثائق السفر المسروقة والضائعة، وسوف نسعى إلى الاستفادة بشكل كامل من هذه الأداة، حسب الاقتضاء، ولا سيما عن طريق تبادل المعلومات المنصلة بجرائم السياسة

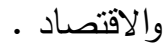
والإرهاب لم بعد مجرد ظاهرة بسيطة تظهر ثم تختفي، بل أصبح واقعاً ألبياً يعاني منه

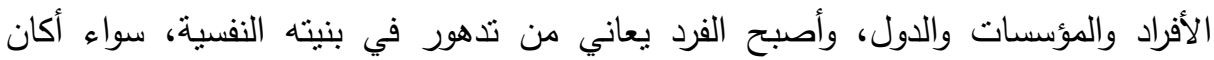

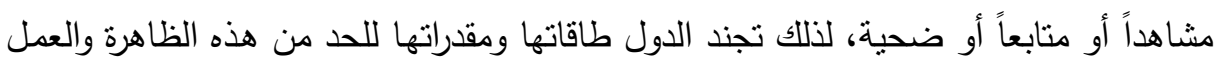

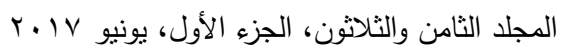


على اجتتانها لكي تحفظ إنسانية الإنسان وتصون كرامته. ويشكل الإرهاب أحد الموضوعات المهمة والمعاصرة التي تحظى باهتمام كبير في المجالات السياسية، والعسكرية، والاقتصادية والاجتماعية، والتربوية والنفسية. والدليل على ذلك ما نقرؤه ونسمعه ونشاهده يومياً من أحداث في شتى وسائل الأعلام حتى أصبح الإرهاب حقيقة نعيشها ونتعايش معها في حياتتا اليومية.

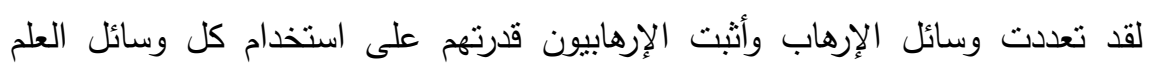
الحديث وتطبيقاته في سبل الوصول إلى أهدافهم، واتسمت العمليات الإرهابية بالخطورة

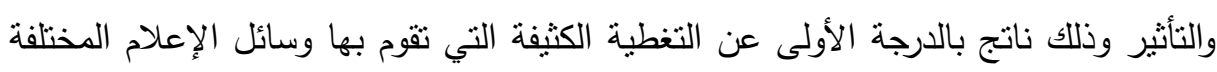

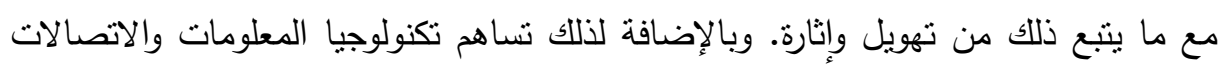
في سرعة انتشار أخبار الإرهابيين، وهذا قد يساعد على تفاقم الإرهاب الدولي.

\section{همهحلة التراسة}

إنَّ المُطلَّعَ على الثُراث الاجتماعيّ للمُجتمع المصري يُلاحظ أنَّ المُحلِّيِن، والباحثين

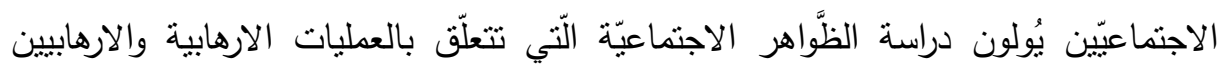

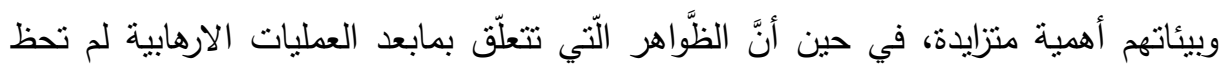

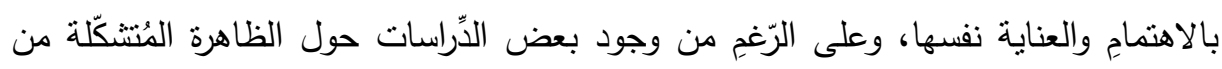

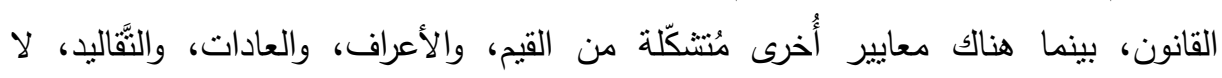

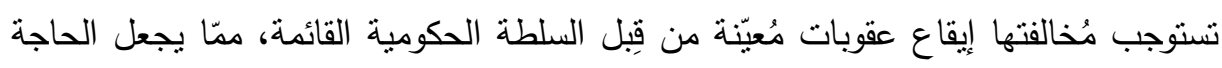

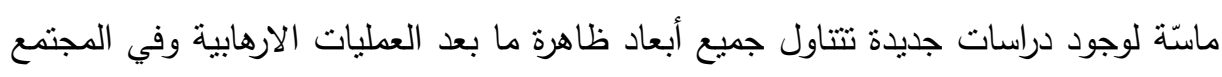
المصري.

لاشك أن العمليات الارهابية عندما تحدث في مجتمع قد يكون لها دور في تعطيل جهود

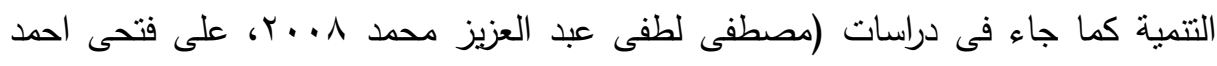

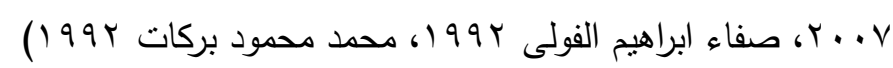

وفي بعض الاحيان يكون للعمليات الارهابية أثنار سلبية تؤثر على منظومة القيم داخل

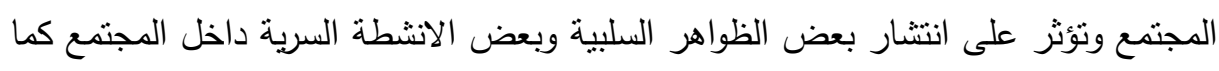

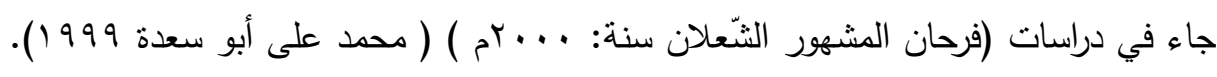

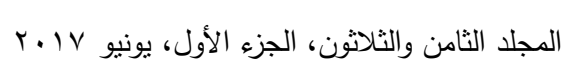


وتزك هذه المشكلات بدون علاج يؤدى إلى تدهور دور الدولة في احداث التتمية باعنبارها اللبنه الاساسية في خطط الدولة لاحداث التتمية. وقد وجد الباحثون أن معظم الدراسات التى تضع الحلول لمثل هذه المشكلة دراسات أجنبية أجريت فى بيئات تختلف ثقافياً عن البيئة الدصرية ونتيجة لندرة الدراسات العربية فالدراسة الحالية سوف تسعى إلى نلافى هذا القصور فى الدراسات العربية.

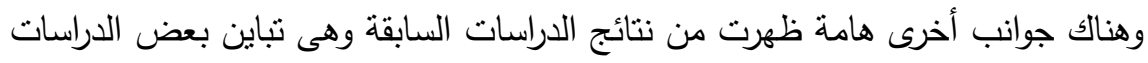

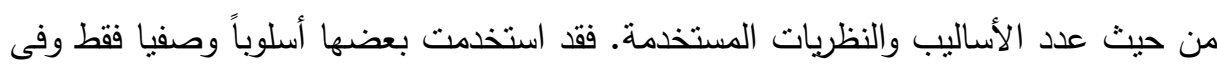
جانب آخر استخدمت بعض الدراسات الوصف والتحليل والمقارنه

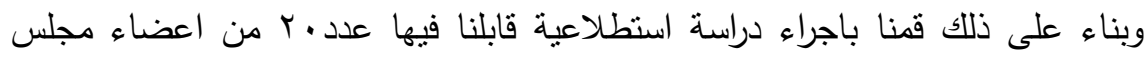

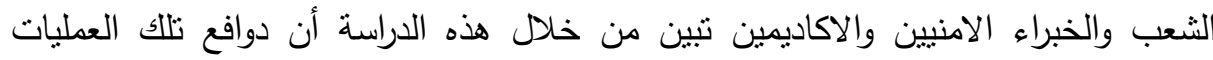

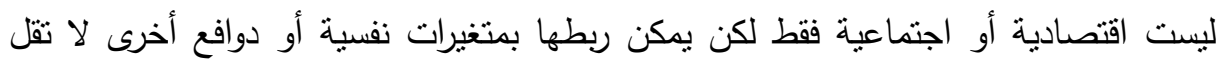

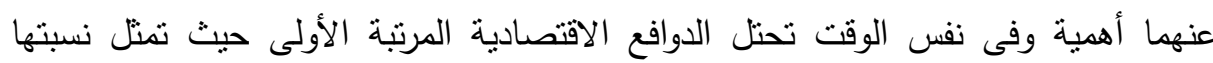

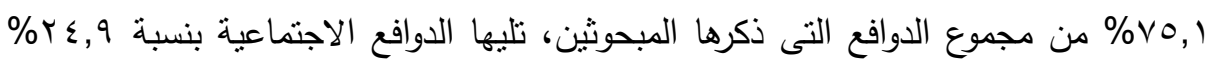

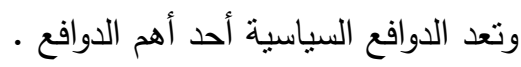

كل ذلك أوضح ضرورة وجود دراسات جديدة تتتاول الابعاد المختلفة للعمليات الارهابية

$$
\text { في المجتمع المصري. }
$$

كما قام الباحث بتتاول المشكلة محل الدراسة مع المتخصصين والدارسين والممارسين وكذا تتاول المتغيرات والجوانب المختلفة للمشكلة، أو النتائج والحلول المحتملة وإجراء دراسة لماتس مقارنة بالدراسات السابقة ومتغيرات جديدة، ومن سرد هذه المشكلة وارتباط الارهاب بالجريمة المنظمة لأنها أحد أثنالها الهامة، كان علينا أن نصيغ إثكالية الدراسة في شكل تناؤلات التات لتشخيص المشكلة حتي يمكننا من وضع الحلول المناسبة للحد من انتثارها والتصدي لها وتقسير ظاهرة مابعد العمليات الارهابية وخضوع العالم والكثير من المنظمات في ازمة مابعد مند

$$
\text { العمليات الارهابية. }
$$




\section{تصاولائش التصاسمة}

التساؤل الرئيسي: كيفة تحقيق إستراتيجية مواجهة المشكلات البيئية والاجتماعية الناتجة عن العمليات الإرهابية في المجتمع المصري؟ ومن هذا التساؤل الرئيسي تنبثق عدة تساؤلات فرعية هي:

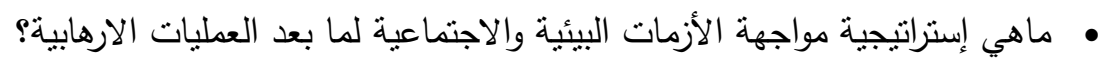

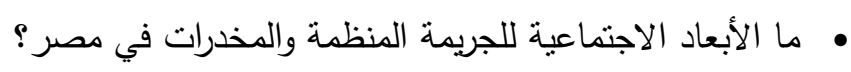

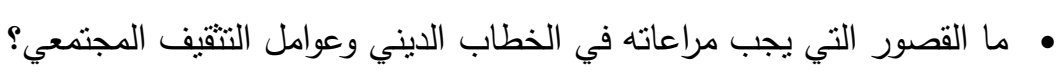
• هل هناك تصور علمي حول أهم الانعكاسات المترتبة على انتتار ظاهرة الجريمة

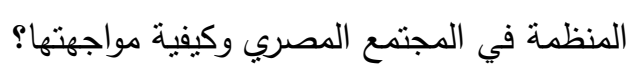

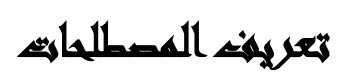

الاستراتيجية: فيما يلي عدد من التعريفات حول مصطلح الاستراتيجية قمت بجمعها من عدة مراجع ذكرتها في النهاية، أرجوا أن يكون فيها النفع والفائدة.

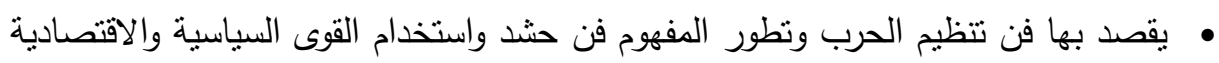
والتكنولوجية والنفسية والعسكرية وتحريكها في نسق متكامل لتحقيق الأهداف التي تضعها

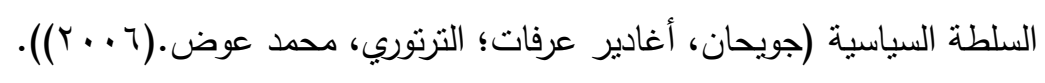

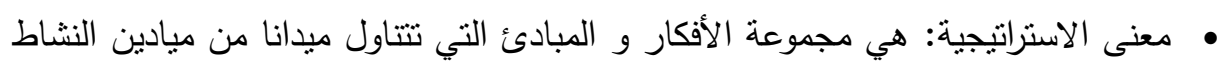
الإنساني بصورة شاملة ومتكاملة، وتكون ذات دلالة على وسائل العمل، ومتطلباته

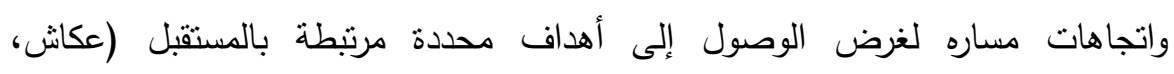

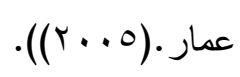

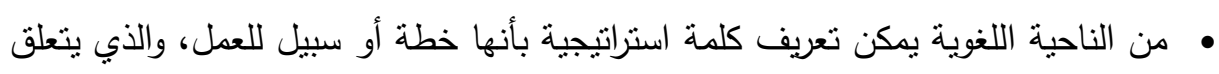

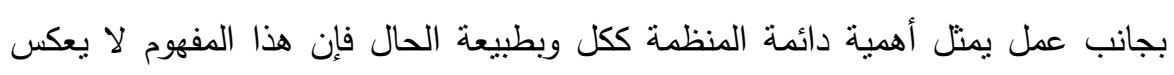

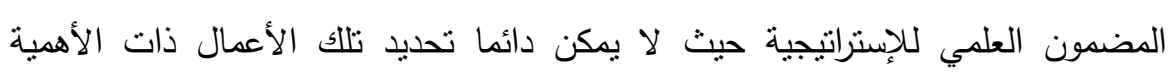

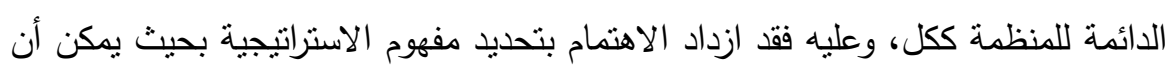

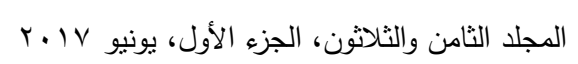


تساعد في تطبيقها واستخدامها من قبل القائمين على ممارسة العمليات الإدارية للمنظمة ووفقا لوجهة النظر هذه فإن الاستراتيجية هي خطط وأنشطة المنظمة التي يتم وضعكها بطريقة تضمن خلق درجة من التطابق بين رسالة المنظمة وأهدافها وبين هذه الرسالة

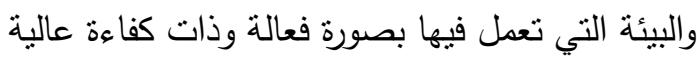
- تعريف BYRS: "هي عملية تحديد الأهداف والخطط والسياسات المناسبة للظروف البيئية التي تعمل في ظلها المنظمة، والتي تتضمن عملية تحديد وتقويم البدائل المتوفرة

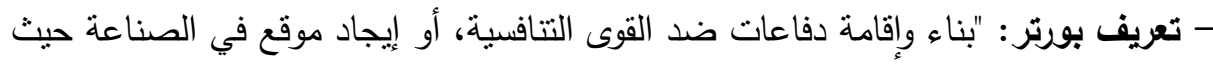

$$
\text { تكون القوى أضعف" (أبراش، إبراهيم.(r . . r)). }
$$

- التعريف الأجرائي:" أن الإستراتيجية هي مجموعة السياسات والأساليب والخطط والمناهج

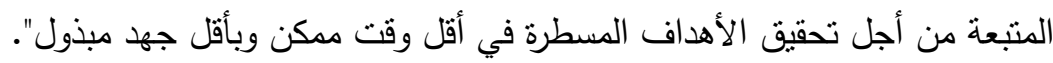

تمثل الأزمة إنهيارا" للهياكل المألوفة التي تمنح النظام السياسي والاجتماعي القائم شرعيته، وتهدد القيم الجوهرية التي يرتكز عليها، كونها موقفا" غير اعتياديا" وغير منوقعا"

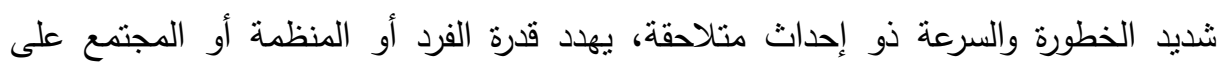
البقاء. والأزمة لا تشمل التهديد فقط أنما الفرصة للتغيير كذللك ـ مما يجعلها مفهوما" معقدا" وغنيا" وجدليا" ذو متلازمة لفظية وطرفين متضادين ينبغي التوفيق بينهما وهذا ماذهب إليه (Morin,1976)

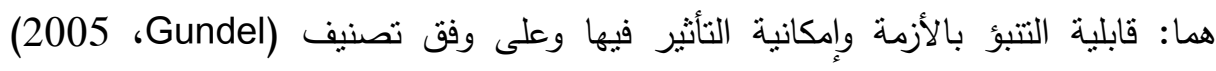

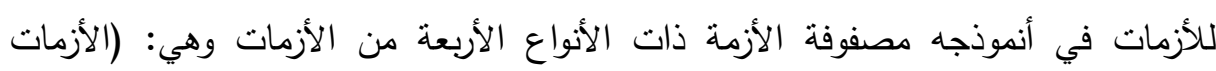

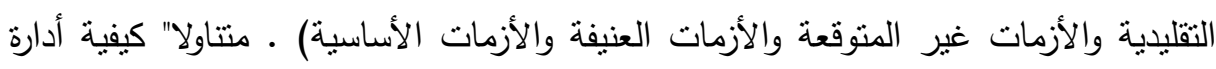
الأزمة بنجاح بجانبيها ألأعلامي والسيكولوجي بأن تكون الاستجابة صحيحة وسريعة واستثنائية

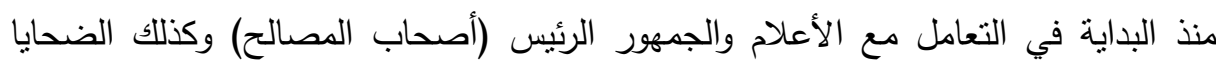
لاستعادة الثقة وإعادة بناء العلاقات وترسيخ مصداقية المنظمة، مما يقلل من حجم الضرر الذي يمكن أن يصيب سمعة المنظمة ويخفض ضغط الأعلام ومستوى التغطية الإعلامية 
اللازمة ويقلل من قوة الخصوم عند تحمل المسؤولية في تحديد الأضرار والتعويضات وفق

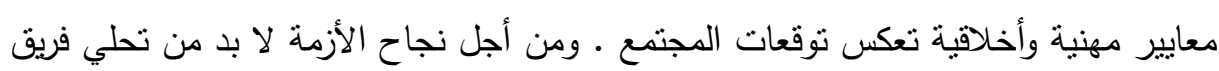

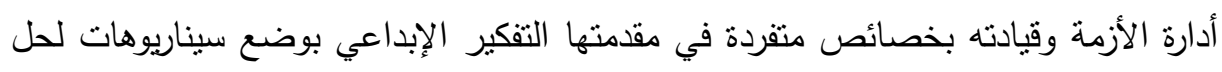

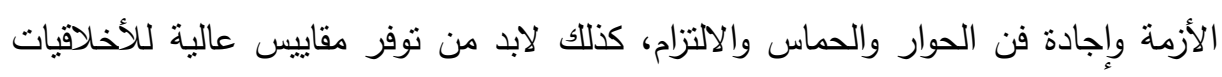

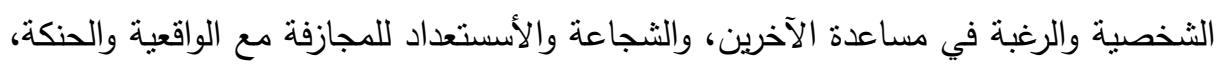

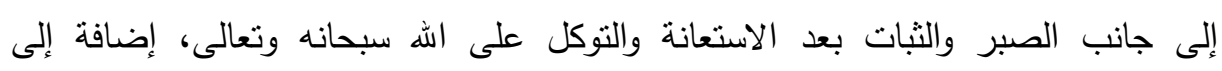

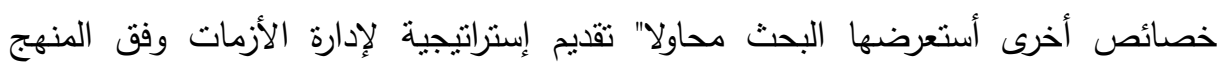

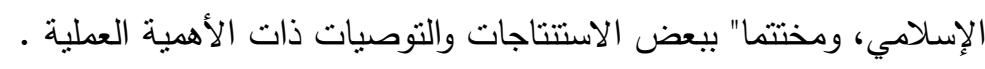
نظريات تفسير الإرهاب:

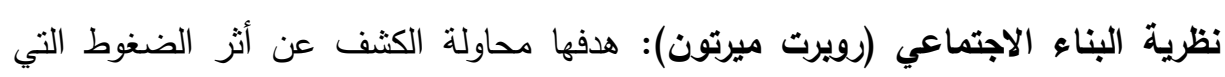

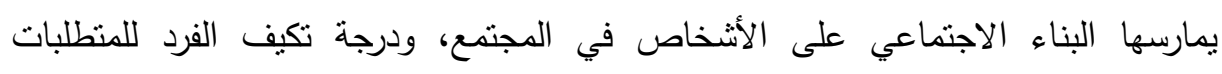

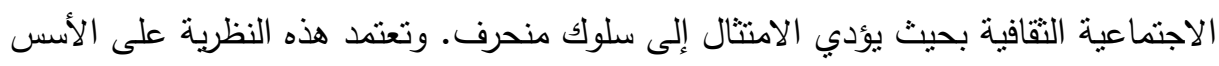

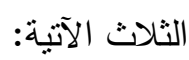

• الطموحات أو الأهداف التي يتلقاها الأفراد ويؤمنون بها من خلال الثقافة التي يعيشون فيها. • المعايير الاجتماعية التي تحكم مسيرة الأفراد في تحقيق طموحاتهم.

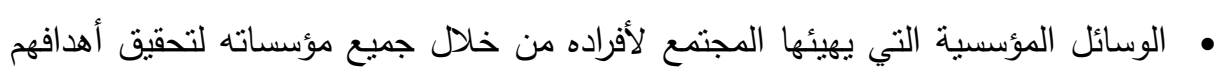
وطموحاتهم.

نظرية الصراع: هي نظرية ماركسية فحواها أن الصراع الطبقي يحدث في مرحلة معينة من تطور المجمعات، وتظهر التناقضات بين القوى الاجتماعية بناء على ملكية وسائل الإنتاج. وهذا التناقض الطبقي -في نهاية المطاف- يؤدي إلى عنف سياسي يتمثل في ثورة البروليتاريا على الطبقة البرجوازية المالكة لوسائل الإنتاج.

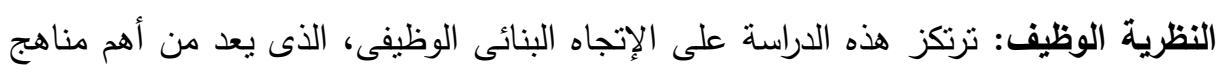

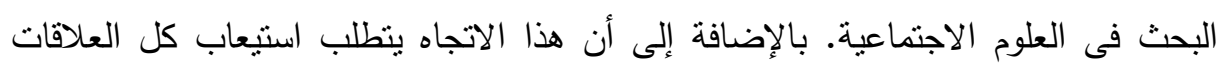
الاجتماعية المكونة للبناء الاجتماعى المستمر عبر الزمن، هذه الاستمرارية تتسم بالديناميكية.

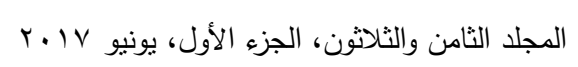


لذا، يعد هذا الاتجاه من أنسب الاتجاهات لدراسة المجتمعات المتغيرة. والمجتمع عبارة عن أجزاء هذه الأجزاء لبست منفصلة عن بعضها فهى فى النهاية تعتبر وحدة متماسكة، لوجود النهات تفاعل وتساند وظيفى بينها. والاتجاه البناء الوظيفى يفترض عن داءه دراسة أى مجتمع وجود علاقات متبادلة وتساند وتفاعل بين النظم السائدة فى المجتمع بحيث يتعذر فهم أى نظام دون بناه

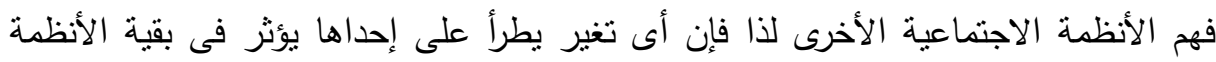

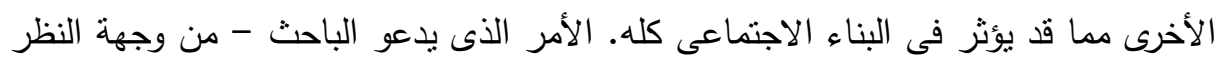
البنائية الوظيفية - عند دراسته لخصائص البناء الاجتماعى أن يحلل نظمه الاجتماعية ويتعرف على العلاقات المنبادلة القائمة بينها. المشكلات البيئية الناتجة عن العمليات الارهابية سيثير الباحث فى الصفحات المقبلة عبارة عن صراع ثقافى واجتماعى يشمل كل نظم وثقافة المجتمع، وبالتالى تؤدى إلى ظهور عناصر جديدة للتكيف الاجتماعى والثقافى،

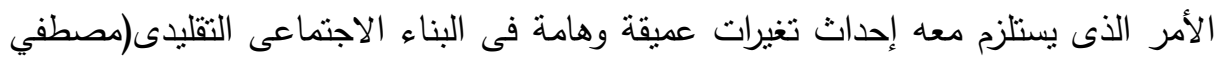

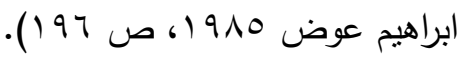
فالعمليات الارهابية التي غالبا ما تتتج عن عوامل اقتصادية فى المقام الأول كثيراً ما

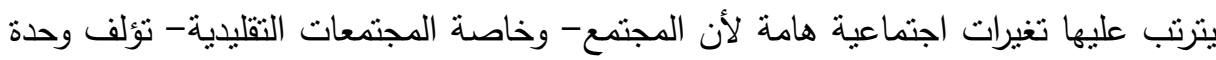
عضوية متكاملة ومتماسكة، وأى تغير يصيب أى نظام يؤدى إلى تغير ممانل فئل في الأنظمة

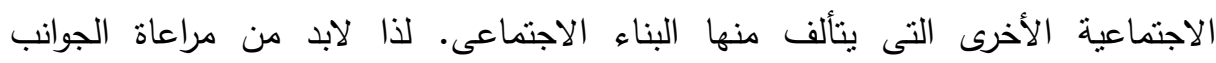

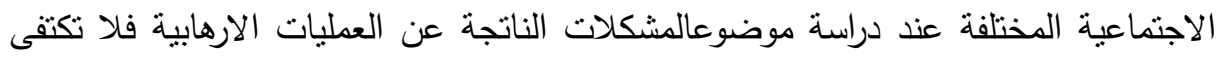
بدراسة الجوانب الاقتصادية بل ندرس أيضاً كل نظم وثقافة المجنمع، لكى نتجنب الأخطاء التى قد تحدث عند تتفيذ أى مشروع يتتاقض مع الأفكار الدينية، أوالقيم الخلقية الموروثة.

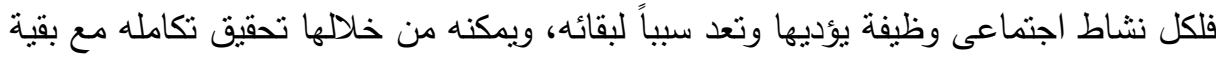

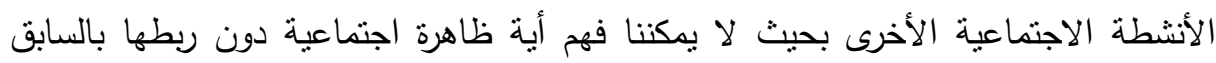

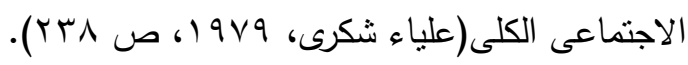
نظرية الاختلاط التفاضلي: وهي تطوير منهجي لشرح كيفية انتقال السلوك الإجرامي عن طريق التعلم من الآخرين. والفرضيات الأساسية التي تقوم عليها هذه النظرية هي: 
• أن السلوك الإجرامي سلوك غير موروث يكتسبه الإنسان بالتعلم.

• بتعلم الثخص السلوك الإجرامي عن طريق التفاعل مع أثخاص آخرين.

• • بحدث في إطار علاقات أولية ذات طبيعة شخصية حميمية وعلاقة ودية.

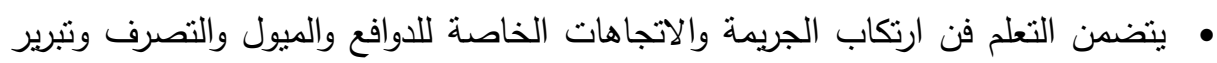

التصرف.

• الاتجاه الخاص للدوافع والميول يتم تعلمه من تعاريف النصوص القانونية سواء أكانت

مناسبة أو غير مناسبة.

• ينحرف الثخص حين تبرمج عنده كفة الآراء التي تحبذ انتهاك القوانين كفة الآراء التي تئي

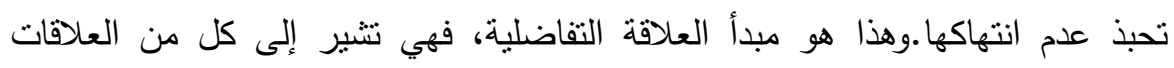
الإجرامية والعلاقات المقاومة والتي يجب أن تعمل مع القوى المكافحة.

• قد تختلف العلاقات التفاضلية في تكرارها واستمرارها وأسبقيتها.

• • تعلم السلوك عن طريق النماذج الإجرامية والمعادية للإجرام.

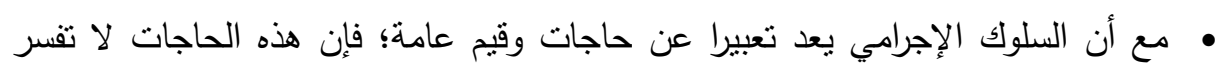

هذا السلوك لأن السلوك غير الإجرامي تعبير عن نفس الحاجات والقير.

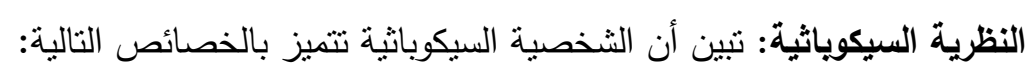

(1) نظهر النزاعات السيكوباثية منذ سن مبكرة في صورة أعمال مضادة للخلق أو في صورة

تكبر وتحد لسلطة الكبار .

(r) يبدي السيكوباثي ميلا عاما للإشباع الفج والأشكال البدائية من الغريزة.

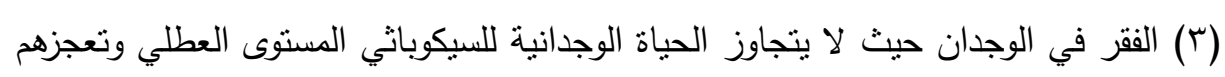

عن تمثل القيم.

(ع) فجاجة الانفعال حيث يميل التفريغ الانفعالي إلى أن يكون انفجاريا، ويظهر في فترات

$$
\text { غير عادية. }
$$

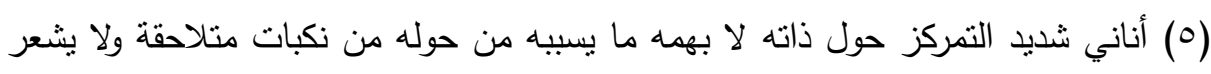

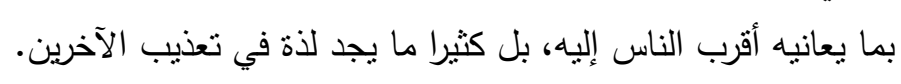

(7) يتصرف دون تفكير مسبق ويتميز سلوكه بالاندفاعية، ينطلق إلى إرضاء رغباته العاجلة.

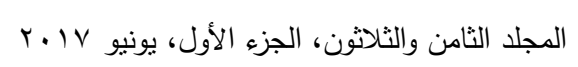


وتؤكد دراسة هذا التفسير في توضيحه الدافع الذي يحبط وينتج عنه العدوان إذ نرجع نشأة العدوان إلى أثر الثواب والعقاب والى التقليد نتيجة وجود نماذج عدوانية. كما أن الإحباط

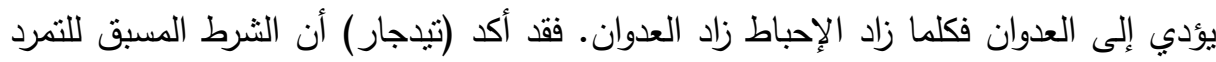

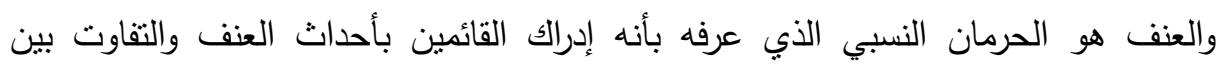
توقعاتهم وتصوراتهم للأوضاع التي يعتقدون بأنهم جديرون بالحصول عليها بشكل مبرر، وبين

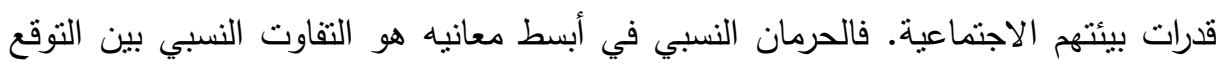

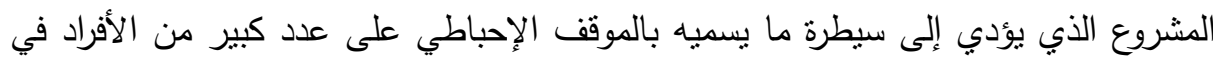

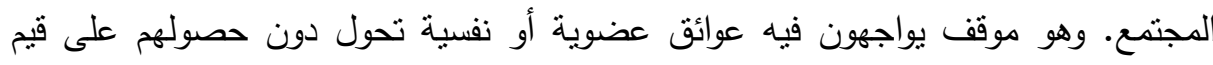

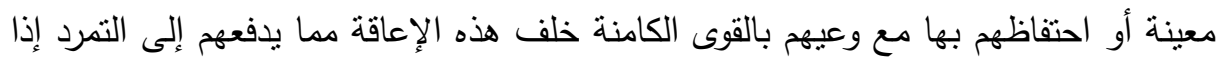

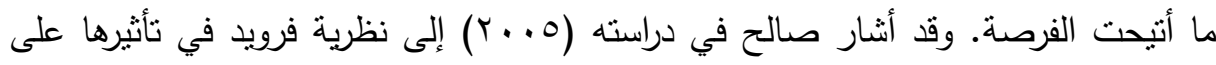

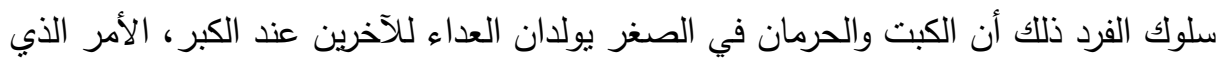
يولا حالة حب الذات وانفصام الثخصية والطاعة العمياء. لكن صالح في دراسته بين أن هذه أنه

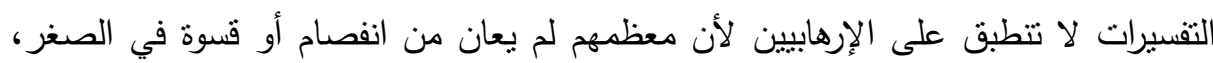
كما أن الانطوائية تتاقض صفات العمل الجماعي المطلوبة في المنظمات. نظرية التبعية وقضايا الارهاب وعلاقة بالبيئة والتنمية: ظهرت التهاعية نظرية التبعية في الستنيات لتنحض نظرية التتمية الغربية وتقدم أساسا جديداً لتفسير ظاهرة التخلف في العالم الثالث (التابع) يقوم على قضية أساسية مفادها ؛أن علاقة التبعية والاستغلال التى تعرضت لهابـ لها الدول

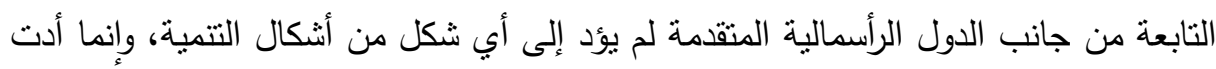

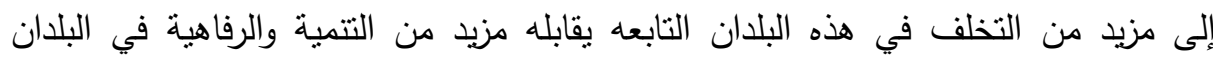

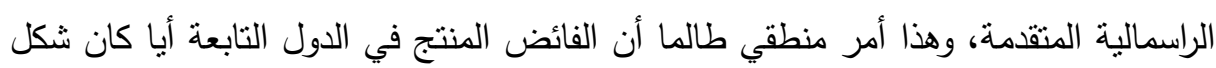
انتاجه ينقل باستمرار إلى مركز العالم الرأسمالي المتقدم. نظرية الفوضى الخلاقة: تعتمد نظرية الفوضى الخلاقة في الأساس على ما أسماه ( صموئيل

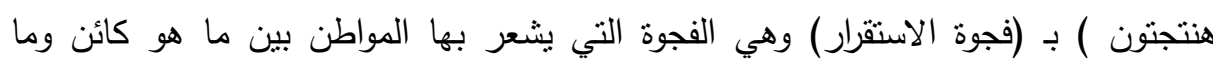

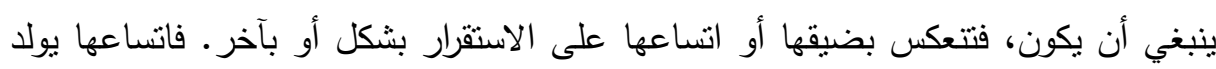

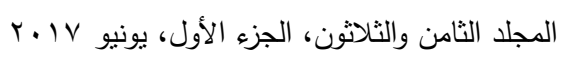


إحباطاً ونقمة في أوساط المجتمع، مما يعمل على زعزعة الاستقرار السياسي، لاسيما إذا ما

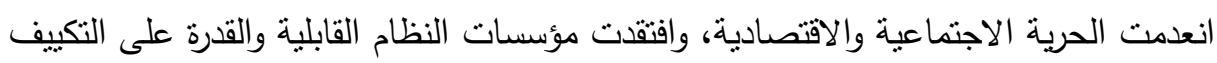
الايجابي، ذلك أن مشاعر الاحتقان قد تتحول في أية لحظة إلى مطالب ليست سهلة للوهلة

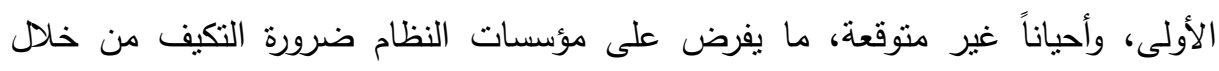

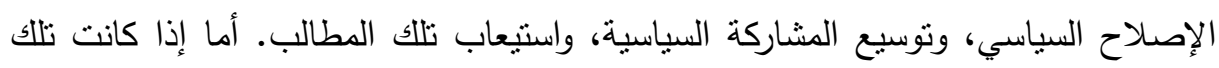

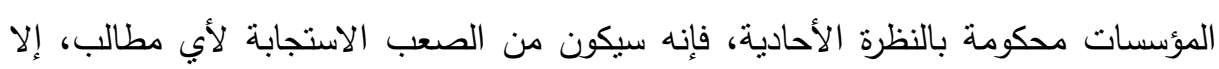

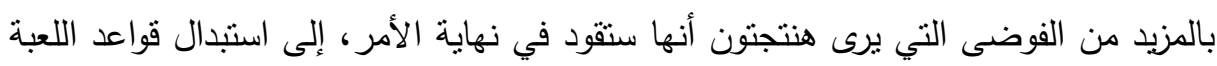
واللاعبين.

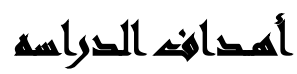

يتحقق الهذف الرئيسي للبحث محل الدراسة التوصل إلى إستراتيجية مواجهة المشكلات البيئية والاجتماعية النتاجة عن للعمليات الإرهابية. وكي يتحقى هذا الهـف لابد من تحقى أهداف فرعية أخرى.

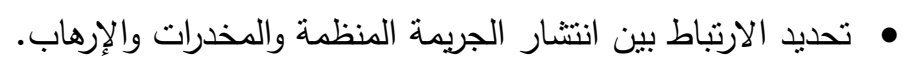

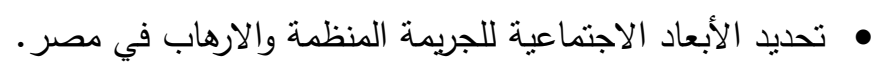
• تحديد أوجه القصور في الخطاب الديني والتتقيف المجتمعي.

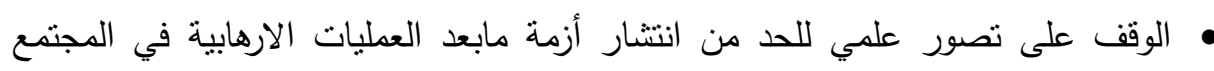
المصري وكيفية مواجنتها.

\section{أهمية التصواسم}

يمثل الإرهاب نهديداً خطيراً لسائر الدول وكافة الثعوب، وهجوماً مباشراً على القيم

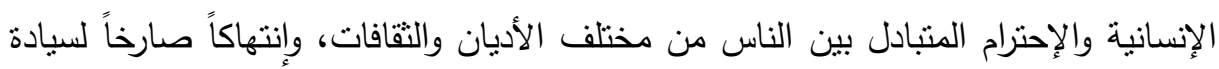
القانون والمواثيق والأعراف الدولية. 
وقد شهدالعالم فى الآونه الأخيرة العديد من الأنشطة الإرهابية التى تجاوز مداها حدود

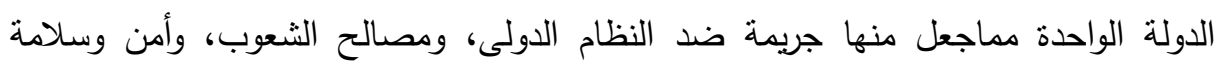
البشرية وحقوق الأفراد الأساسية.

ويؤكد لنا التأصيل التاريخى لظاهرة الإرهاب أن هذه الظاهرة ليست وليدة منطقة بعينها أو ديانة بذاتها، وإنما هى إنعكاس مادى لعوامل القصور فى التعامل الدولى مع المشكلات السياسية والإقتصادية والإجتماعية.

وتتعدد الجهود الوطنية والإقليمية والدولية لمواجهة ظاهرة الإرهاب، إذ نوضح أية قراءة متأنية فى تاريخ العلاقات الدولية أن الحاجات الأمنية كانت أسبق الحاجات إلحاحاً وإستلزاماً لإيجاد تتسيق إقليمى ودولى يكفل التعاون والفاعلية فى مواجهتها. • وهناك اهية نظرية حول مفهوم مابعد العمليات الارهابية واثرة على المجتمع والبئية. • همية وضع استراتيجة لتعامل مع الاثار مابعد العمليات الارهابية.

\section{التراسائ المايرهي}

هذا، ويمكن أن نستعرض الدراسات السابقة حول الإرهاب والأسباب المؤدية له، ثم

$$
\begin{aligned}
& \text { الدراسات التي تدور حول الوقاية منه وعلاجه. } \\
& \text { سيكولوجية الإرهاب: }
\end{aligned}
$$

بيّن فاضل(^ . . ץ) في دراسته بوجود نمط من الثباب الذين فثلوا في دراساتهم، أو لم يحققوا

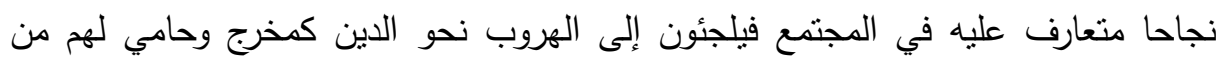

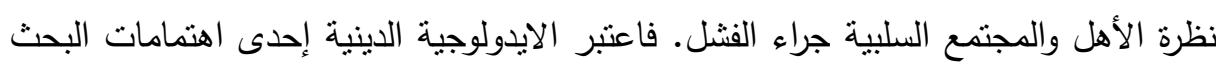
لدى المراهق لتحقيق ذاته واثبات تفوقه.

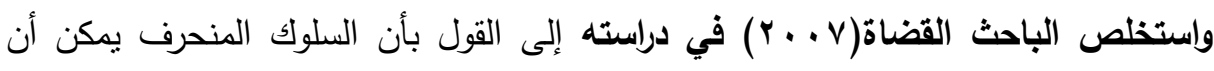

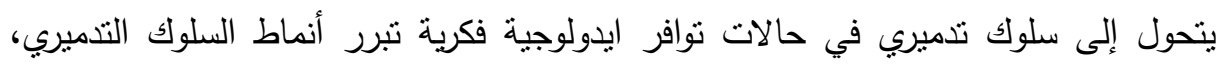
وقابلية الإيحاء لتقبل الأفكار وتتفيذها على أرض الواقع، وتدريب عسكري مكثف، والفرصة 
السانحة لتحول مشاعر سالبة إلى أنماط سلوكية على أرض الواقع، والتطرف على المستويات الثناث.

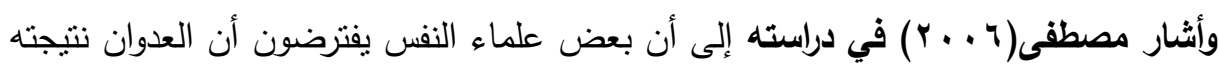

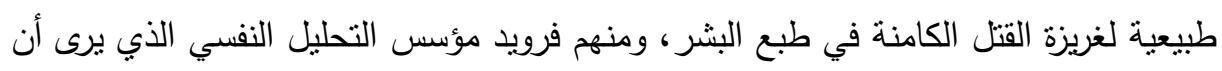

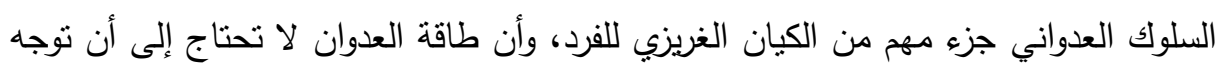

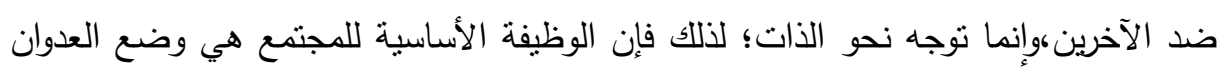

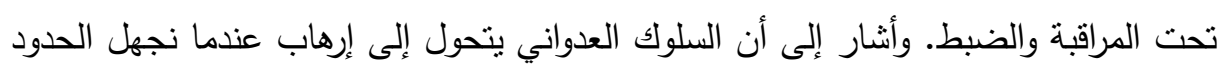

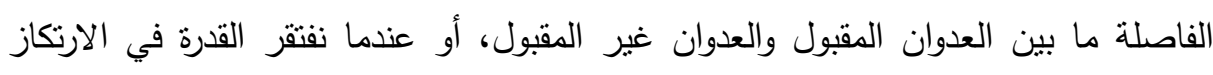

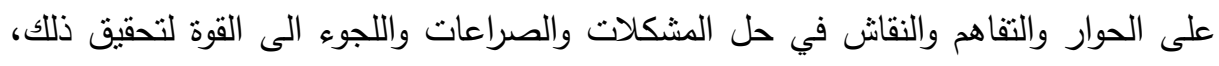
الأمر الذي يعطي مبررا وشرعية لاستخدامه.

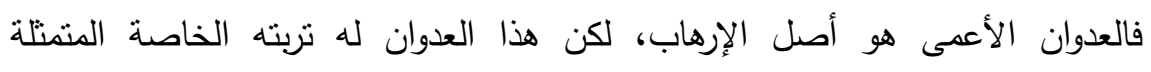

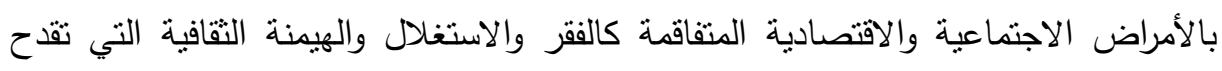

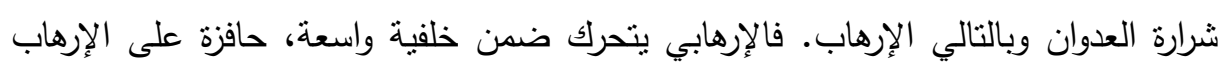

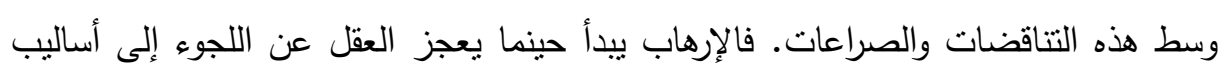

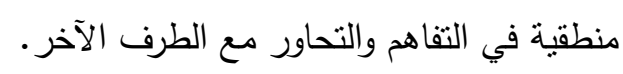
وقد حاول عكاش(ه . . r) أن يظهر أن الكارثة المعنوية يفوق نأثيرها عن الكارثة المادية.

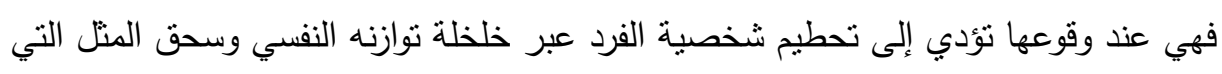
تربي عليها كونها تمنل خطوطا دفاعية تحمي الإنسان وتحقق وجودهن، فتحوله إلى إنى إنسان

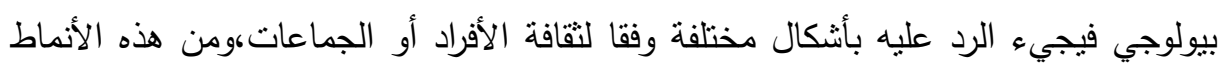

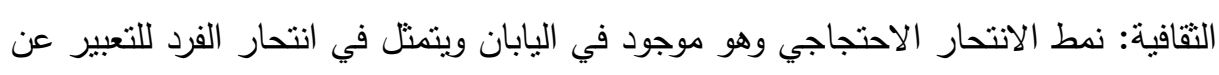

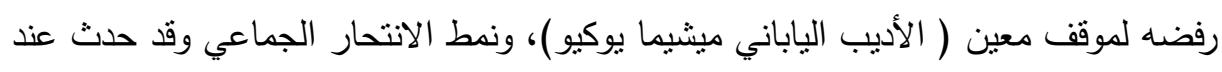

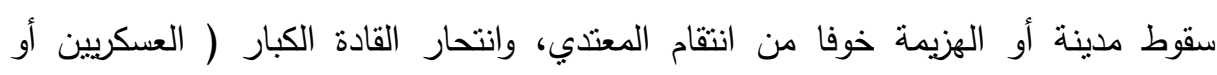

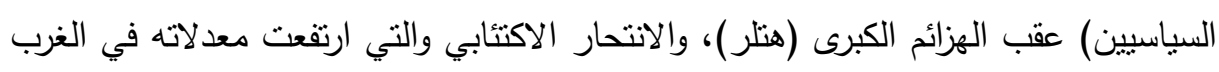

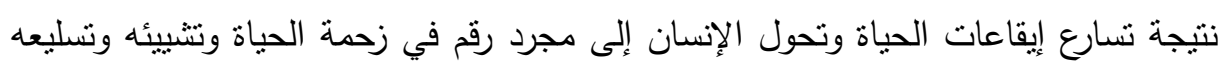

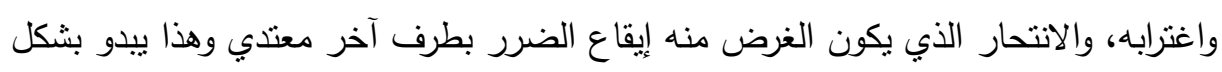

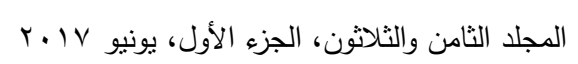


خاص في حالة الاحتلال. كما وضح بأن سيكولوجية الإرهاب في المجتمعات العربية بأن الإرهاب أو العمليات الانتحارية أو الاستشهادية ظاهرة اجتماعية تتدرج في إطار الإنهاب النسق

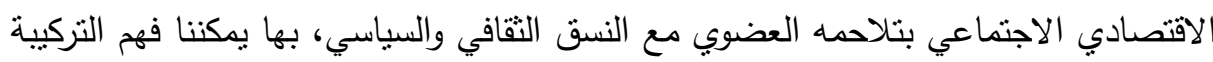

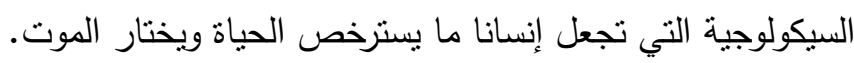

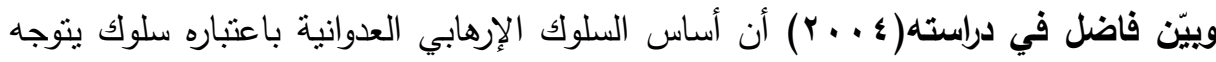

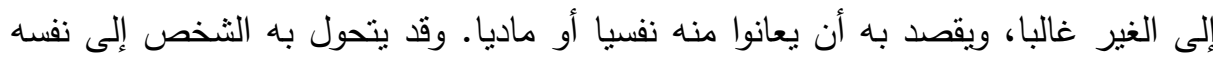
فيلحقه منه الضرر وقد بصيبه الدمار .

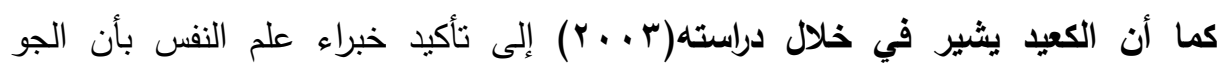

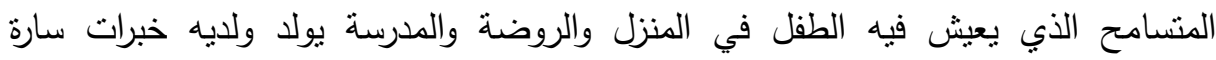
ويساعده على تقبل ذاته، أما البيئة غير المتسامحة التي تعتمد العقاب البدني أو المعنوي

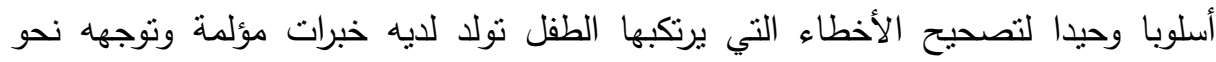
العنف والإيذاء والعدوان الموجه نحو الذات أولا، ومن ثم إلى الآخرين. فلا هو يستطيع أن بـان

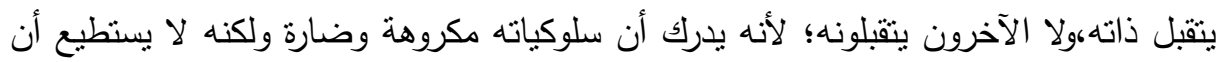
يتخلى عنها.

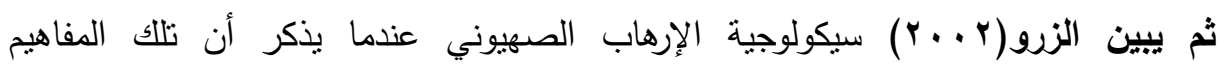
والمنطلقات السياسية والفكرية والاجتماعية للإرهاب الصهيوني والموثقة في عدد لا حصر لهابه له

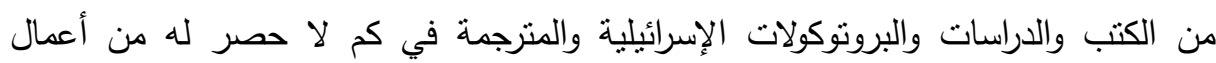

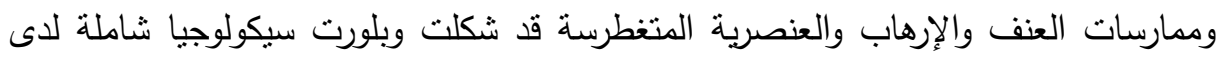
معظم فئات وشرائح المجتمع الإسرائيلي بعد قيام الدولة الإسرائيلية، وبصورة خاصة واضحة

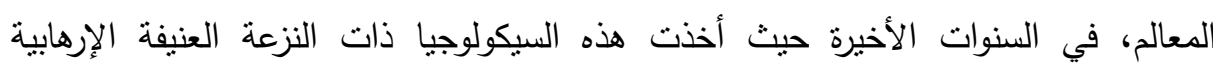
العنصرية تطغى على تفكير وممارسات شتى الجهات، المنظمات والحركات الإسرائيلية بشكل عام. فسيكولوجيا الإرهاب الدموي هي التي تهيمن هيمنة مطلقة على أجهزة الجيش والموساد والثاباك ودولة المستوطنين في اتخاذ الأراضي المحتلة. وطبعا، الذي يعمل على نتئل تشكيل الإرهاب هو فتاوى وتعليم وتتشئة من قبل الحاخامين اليهود في مدارسهم. 
ومن حيث الخصائص الثخصية لصالح التوجه الديني الظاهري في صفات العصابية وتأكيد الذات والجمود والقلق ووجهة الضبط والسيطرة. كما أن معامل الارثباط دال إحصائي

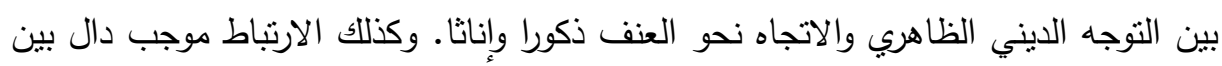

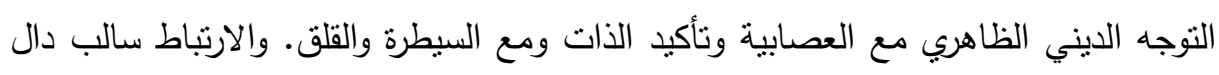
بين التوجه الديني الجوهري مع السبطرة، والارتباط موجب دال مع وجهة الضبط الداخلية

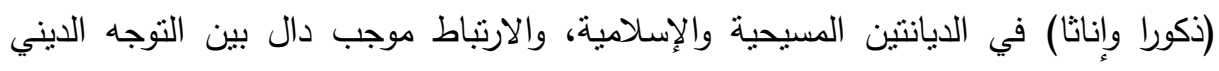

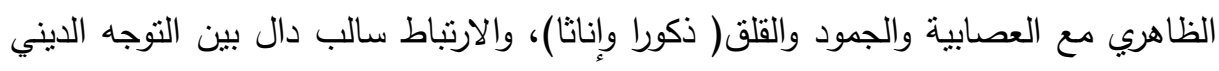

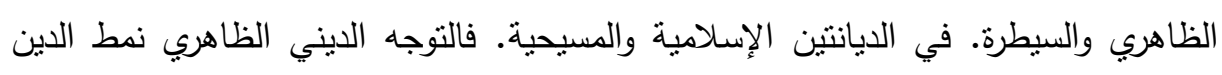

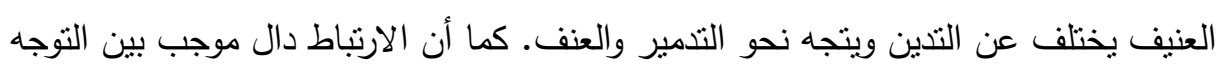

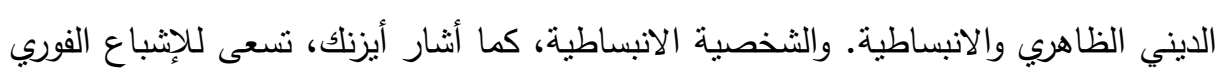
للدوافع العدوانية.

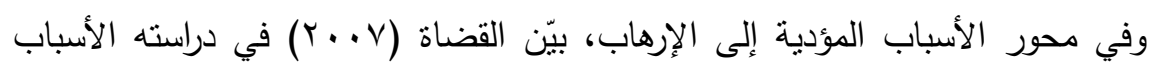

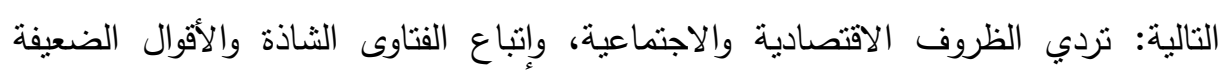

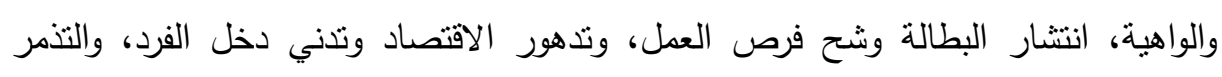

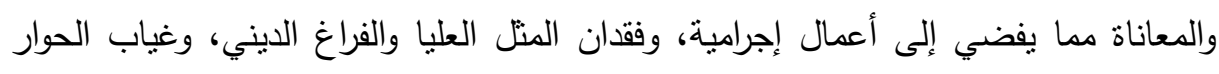

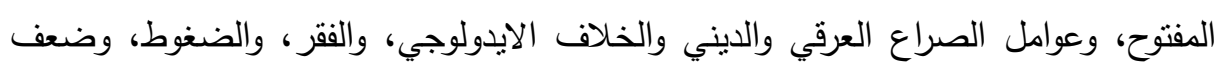

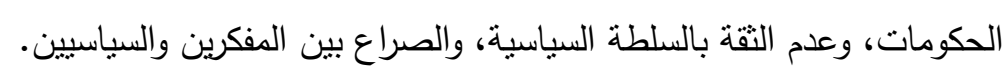

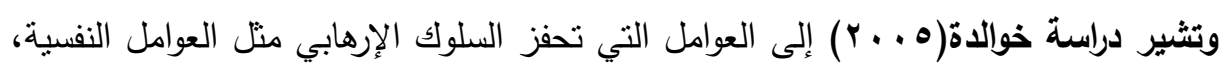

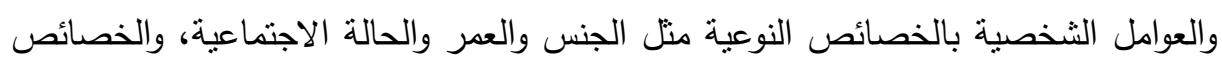
العضوية في الوراثة والتكوين العضوي. والعوامل الطبيعية في المناخ والمكان والتربية في حالة الفقر • والعوامل الثقافية في المستوى التعليمي، والعادات والتقاليد، ووسائل الاتصال، ووسائل والئل الإعلام المقروءة مثل الصحف والروايات الرخيصة، ووسائل الإعلام المسموعة والمرئية

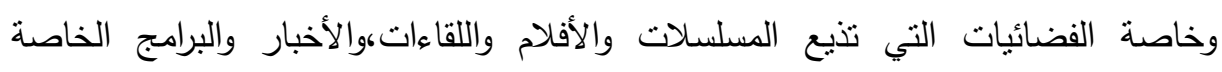
بالجريمة. والعوامل الاقتصادية وخاصة انخفاض المستوى الاقتصادي وعلاقته بالإجرام؛ 
فالجرائم لا تقتصر على المال بل امتدت إلى الجرائم الاقتصادية والاعتداء على الأعراض

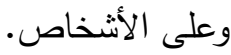

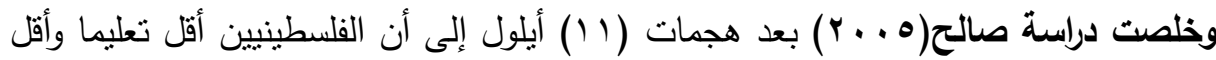
مرتبة اجتماعية واقتصادية لأن معظمهم من معسكرات اللاجئين. وأن الفلسطينيين أكثر معرفة بالغرب وانفتاحا عليه واقل تدينا وعاثوا في لبنان، حيث اعتبرها الغرب من أسباب الإرهاب.

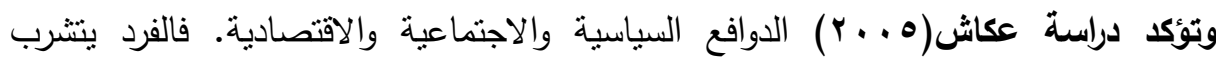

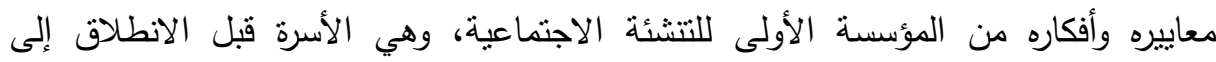

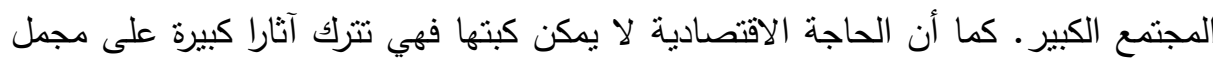

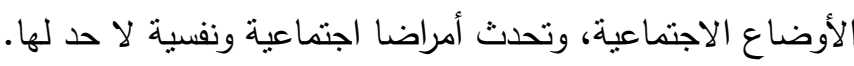
مفهوم الفوضى الخلاقة: دخل مصطلح (الفوضى الخلاقة ) القاموس السياسي في العقدين الاخيرين ،ويتميز بقدر كبير من الالتباس والتاويل يصل الى حد التحايل والتلاعب اللفظي لوصف حقبة سياسية ناريخية صاخبة، وبمسار خارج المالوف الطبيعي للخطاب السياسي - الفكري التقليدي، عبر بناء نسيج من المتقابلات المختلفة للمصطلحات تهدف الى لى تحقيق استراتيجية معينه ومنهج لادارة المصالح الامريكية والغربية في المناطق التي تتركز فيها تلاك المصالح. فالفوضى الخلاقة هي خلاقة بالنسبة لمصالح امريكا والغرب، وغير خلاقة، بل مدمرة بالنسبة للاوطان والثعوب، وهذا المصطلح ينشط في حيز العولمة الرأسمالية وصعود الليبرالية

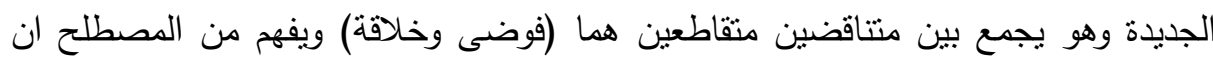

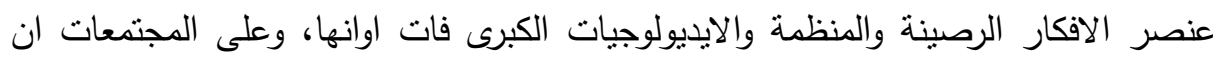
تشلك ممرات كثيرة للوصول الى الجزيرة الاستقرار . مفهوم الجريمة المنظمة: عرفها الدكتور / أحمد جلال عز الدين بأنها : " تتظيم إجرامي

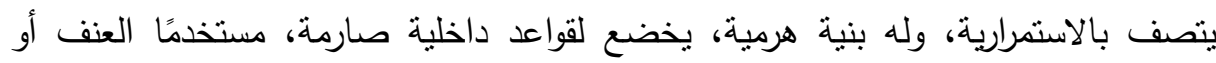

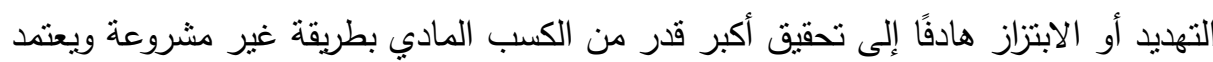
إلى جانب العنف إفساد الموظفين الحكوميين عن طريق الإبتزاز والرشوة ". 
وعرفها سبلسين سورستين بأنها: " مرادف لأعمال اقتصادية نظمت لأغراض القيام بنشاطات

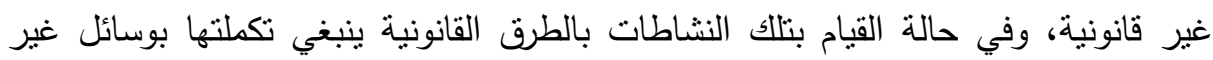

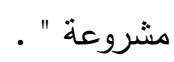
وعرفتها اتفاقية الأمم المتحدة ( باليرمو . .. بم ) بأنها : " نركز في عناصرها الأساسية

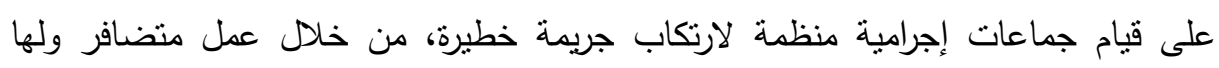
تشعبات في أكثر من بلد، بواسطة الترهيب والعنف أو الإفساد أو غيرها من الوسائل من أجل هن

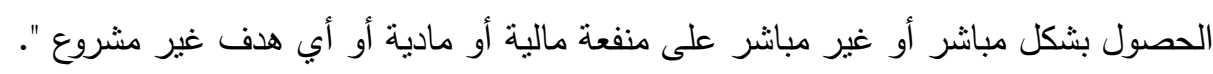

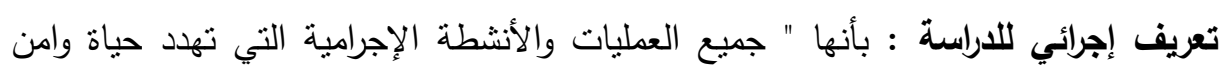

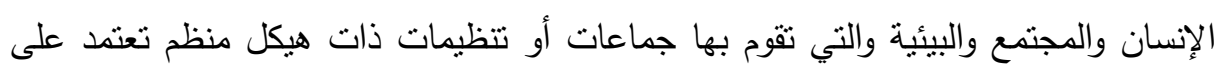
كافة الأساليب التي تمكنها من ارتكاب أنشطتها غير شرعية من أجل تحقيق أهداف ومكاسب

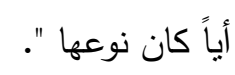

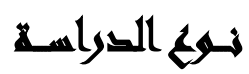

تتنمي هذه الدراسة الى الدراسات السيسولوجية الوصفية التحليلية لكونها أنسب أنواع الدراسات ملائمة لطبيعة موضوع الدراسة والتي تهدف إلى وصف وتحليل طرق مواجة الآثار

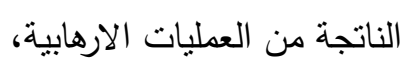

ثم استخلاص النتائج ووضع المؤشرات التي تساعد في الحد من انتشار الإرهاب

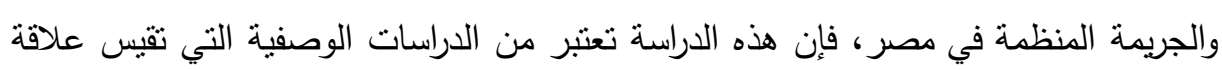

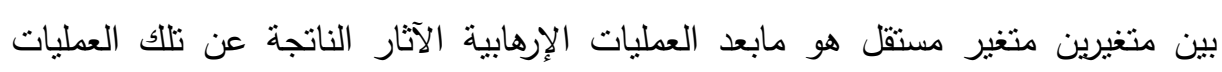

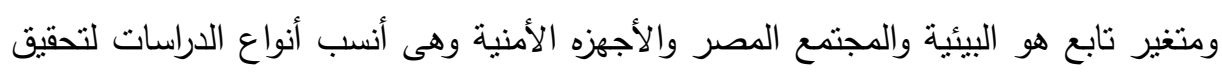
أهداف الدراسة الحالية.

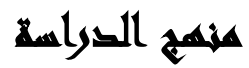

وتنتخدم الدراسة الحالية منهج المسح الاجتماعي بالعينة بهدف الوصول إلى بيانات

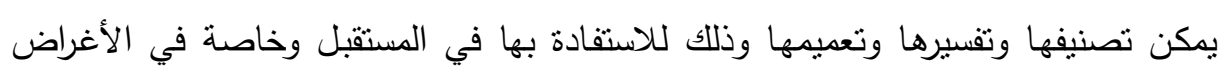


ويتمثل المنهج المستخدم في: المسح الاجتماعي بالعينة للمسؤلين من رجال الأمن ونواب

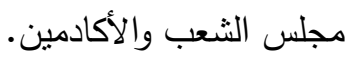

\section{أسواهت التوراسة}

الأداة هي الوسيلة العلمية التي يستخدمها الباحث في جمع بيانات من المفردات في

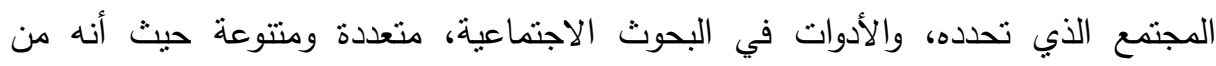
الطبيعي أن تختلف أنواع المعلومات المراد الحصول عليها، وكذلك تختلف أنواع المفردات، حيث أن كل أداه تقيد في موقف معين مع أنثخاص محددون ومع نوع دراسة ومنهج معين،

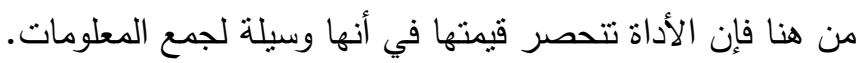

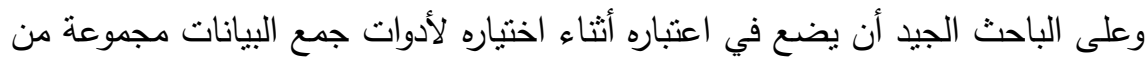
العوامل التي يكون لها تأثير مباشر على تلك الأدوات ومنها طبيعة البحث وطبيعة المبحوثين. واتساقاً مع منطلبات الدراسة الراهنة فقد اعتمد الباحث علي أكثر من أداة لجمع بياناتها من الميدان، بحيث تتفق هذه الأدوات مع مشكلة دراستها وطبيعتها. واعتمد الاراسة الراهنة على الأدوات التالية:

$$
\begin{aligned}
& \text { 1-الاطلاع على الإحصاءات والوثائق. } \\
& \text { r- دراسة الحالة. } \\
& \text { r- الإخباريين. } \\
& \text { ـ - الإحصاءات والوثائق الموجودة فى ال }
\end{aligned}
$$

ه-جهاز المركزي للتعبئة العامة والإحصاء، وكذا في الجمعية الزراعية والوحدة الصحية

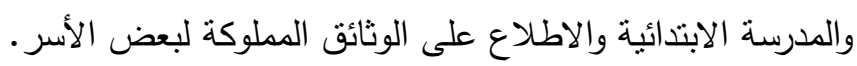
1-دليل المقابلة

دراسة الحالة: هى أداة من أدوات القياس وجمع البيانات للبحوث المنداولة، ويقوم من خلالها باحث أو عدد من الباحثين بطرح أسئلة تتعلق بالقيم والاتجاهات أو الأراء، وتتميز هذه

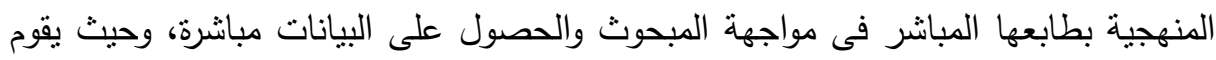


الباحث بتوجيه الأسئلة الثففية واستيفاء الإجابات مبانرة، وتسمح للباحث بالحصول على البهات

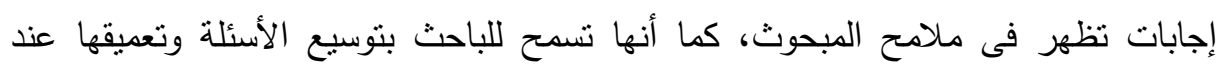

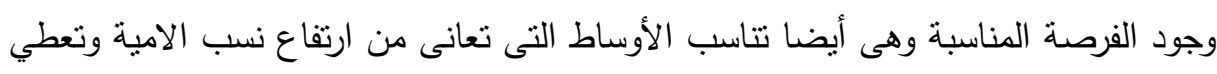

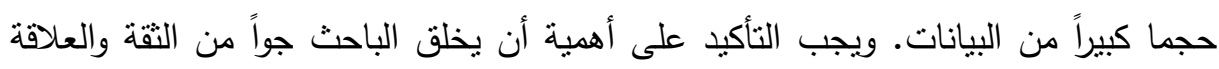

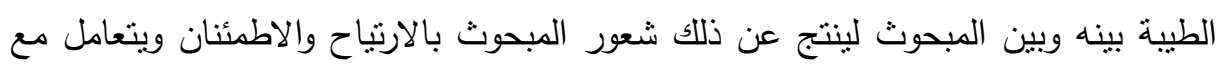

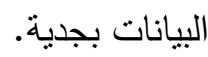

دليل المقابلة: استخدم الباحثون دليلا للمقابلة تناول عدة محاور للتعرف على الحياة الاجتماعية للمبحوثين ممن تعرضوا للعمليات الارهابية شمل البيانات الاولية مثل الاسم،الفئة العئة

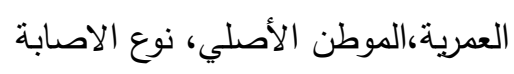

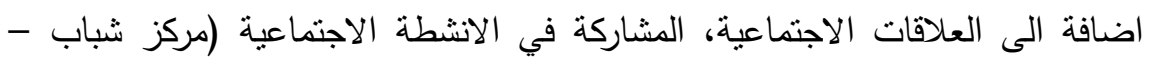

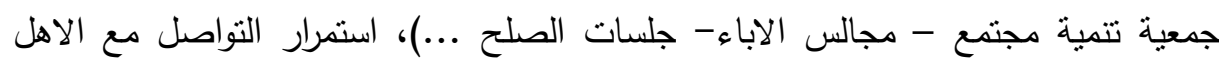

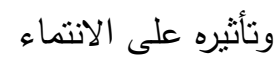
مفرداد الحياة اليومية (أنماط العمل -الانتاج -- مستوي المعيشة - الخدمات - التعليم

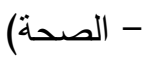

النواحي الاقتصادية: وشملت المهن التي يبرعون فيها (الدادة - تدريب الخيول وتربيتها -

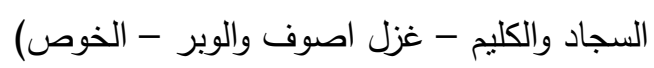

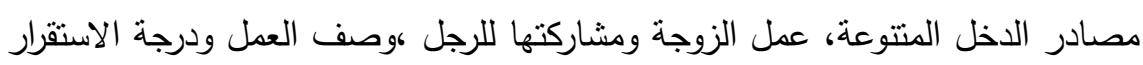

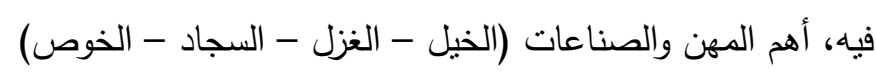
مدي تواجد أنثطة اقتصادية غير مشروعة ورد فعل العائلات اذاء تورط أحد البنائها في الخي ذلك.

النواحي السياسية: الششاركة في الانثطة السياسية المختلفة (ندوات - مؤتمرات انتخابية -

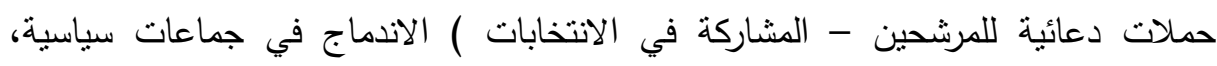

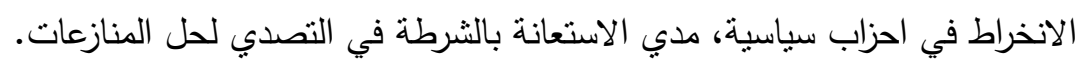

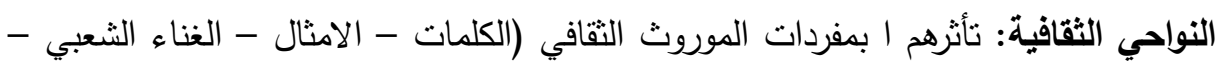

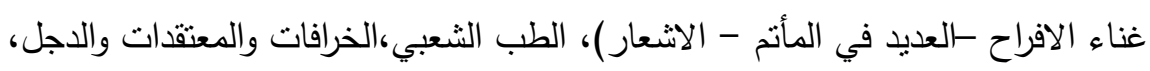
المجلد الثامن والثلاثون، الجزء الأول، يونيو V V. 
الصدق والثبات: تعتبر الأداة صادقة إذا كانت تقيس ما وضعت لقياسه، ولما كانت أداة البحث قد وضعت بهدف التعرف على استراتيجية مواجهة المشكلات البيئية والاجنماعية الناتجة عن العمليات الارهابية فإنبات صدقها من خلال التالي: وق اعتمدت الدراسة على نوعين من الصدق هما: الصدق الظاهرى: وقد قام الباحث فى إطار مراعاة الصدق الظاهرى بعرض دليل الدقابلة على الى عدد من الأساتذة المحكمين بهدف تقييمه وتوضيح رؤيته فى تحقيق الأداة لأهداف البحث، وقد استفاد الباحث من ملاحظات المحكمين الذين قاموا بالاطلاع على دليل المقابلة، وكانت

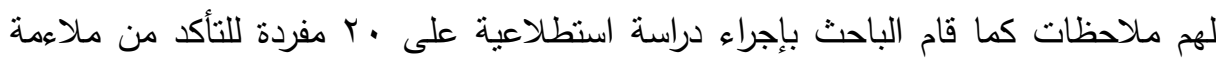

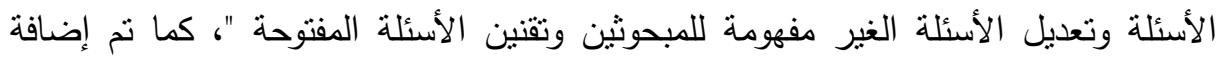
مجموعة من الأسئلة اقترحها السادة المحكمين والمرتبطة جوهريا بموضوع البحث. الثبات: ويقصد به ثبات الاستجابات فى حالة تكرار تطبيق الإداة بمعنى عدم التغير جوهريا،

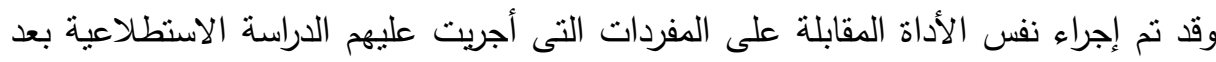
عشرة أيام من الدرسة الاستطلاعية وتم حساب معامل الارتباط بين الاستجابات فى التطبيق الاديق

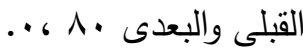
حجم العينة: قام الباحث باختيار V9 مشارك من اعضاء مجلس الشعب ومن رجال الامن

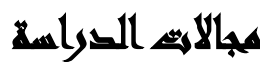

تحددت مجالات الدراسة في المجال المكاني والمجال البشري والمجال الزمني وذلك على النحو

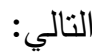
1- المجال المكاني: ةقام الباحث باختبار المجال المكاني للاراسة بالتطبيق على مؤسسات الدولة المعنى بمكافحة الإرهاب والعمليات الإرهابية والجريمة المنظمة في بالي جمهورة مصر العربية. 
r - المجال البشري: تمثل المجال البشري للاراسة الحالية على النحو التالي: عينة عمديه من المهتمين والمتخصيصين في مكافحة الإرهاب والعاملين على الملف الامنى من أكاديمن ورجال أمن وأعضاء مجلس شعب (V9) مفردة مقسمة على النحو التالي:

$$
\vee q=ن
$$

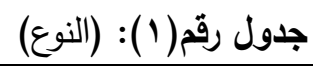

\begin{tabular}{|c|c|c|c|c|}
\hline الترتيب & $\%$ & ك & النوع & P \\
\hline 1 & $\Lambda \Sigma, \wedge$ & $7 \mathrm{VV}$ & ذكر & $\bar{I}$ \\
\hline \multirow[t]{2}{*}{ Y } & $10, r$ & IT & آنتخي & ب ب \\
\hline & $\% 1 \ldots$ & Vq & \multicolumn{2}{|c|}{ المجموع } \\
\hline
\end{tabular}

$$
\vee q=\dot{ }
$$

\begin{tabular}{|c|c|c|c|}
\hline$\varepsilon$ & سَس & الثمن & p \\
\hline $\bar{V}, 9$ & $\xi \Lambda, 7$ & ذكر & $\bar{i}$ \\
\hline
\end{tabular}

جدول رقم(ץ): (بالسن)

ب- المجال الزمني.:تحدد المجال الزمني للدراسة في فترة تطبيق على عينة الدراسة وهى

$$
\text { الفترة من } 0
$$

المعاملات الإحصائية المستخدمة: بعد جمع البيانات ومراجعتها، تم تفريغ البيانات آليا باستخدام برنامج 16.2 الإصدار ، وتم استخدام المعاملات الإحصائية التالية:

$$
\text { 1- المتوسط الحسابي والانحراف المعياري والوسط المرجح. }
$$

r- اختبار (ت) لعينة واحدة من أجل التعرف إلى درجة الكلية ودرجة التوافق الكلية لأفراد عينة

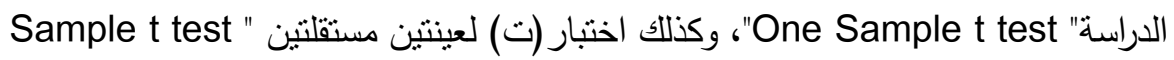

$$
\text { . "Independent }
$$

r- تحليل التباين الأحادي (ONE WAY ANOVA)، كما نم استخدام اختبار شافيه من أجل تحديد موقع الفروق الدالة في حالة وجود الفروق الدالة. 


\section{نمأيج التواسمة}

\begin{tabular}{|c|c|c|}
\hline \multicolumn{2}{|l|}{ ن } & جدول رقم(1): كم عدد الدورات التدريبية \\
\hline الترتيب & ك & عدد الدورات التدريبية \\
\hline$r$ & 7 & دورة واحدة \\
\hline 1 & $\Lambda$ & - \\
\hline$\varepsilon$ & 0 & تثلاثة دورات \\
\hline$r$ & $\mathrm{~V}$ & آربعة دورات \\
\hline & rT & مجموع \\
\hline
\end{tabular}

يوضح الجدول رقم (1) دور الدوارت التدربية التى حصل عليها المشاركين بادئ الرأي،

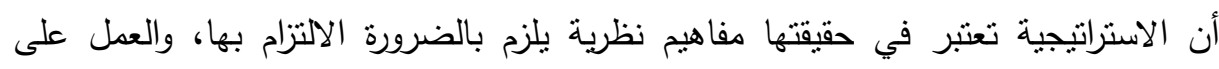

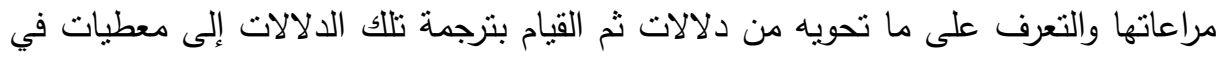

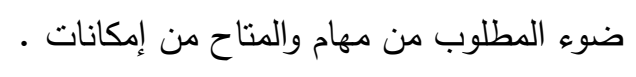

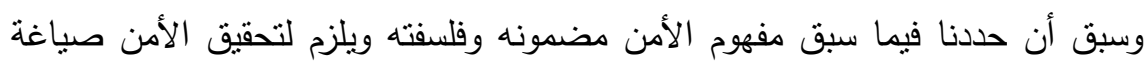

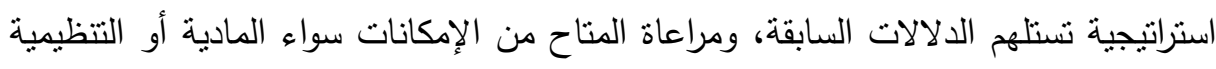

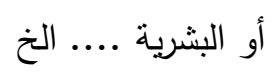
وفي ضوء ما تقلم، فان مقومات الإستراتيجية لا تخرج في مجملها عن:

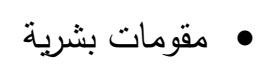
• مقومات مادية • مقومات تتظيمية

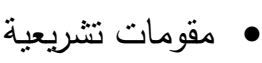

\begin{tabular}{|c|c|c|c|}
\hline \multicolumn{2}{|c|}{ ن } & \multicolumn{2}{|c|}{ جدول رقم(ץ): الخاص بالجهه المنظه } \\
\hline الترتبب & 5 & الجهة المنظمة & م \\
\hline- & $\overline{-1}$ & هبئة أكاديمبة & 1 \\
\hline- & - & هيئة حكومية & $\bar{r}$ \\
\hline$T$ & $\overline{r \tau}$ & هيئة أمنية & $\bar{r}$ \\
\hline
\end{tabular}


يوضح الجدول أهمية مشارة جميع الجهات المعنى لمكافحة الارهاب تعود أهمية البحث الحالي إلى موضوع البحث (الآثار السياسية والأمنية للإرهاب)، ذلك الوباء التهاء اللعين (الإرهاب)

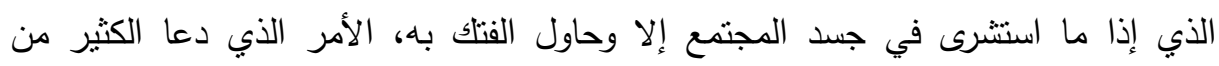

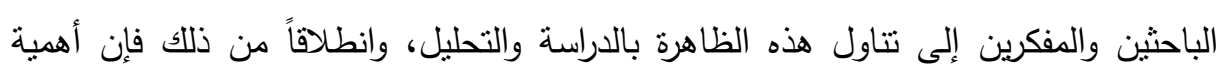

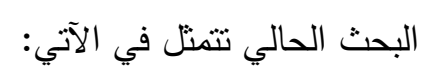

• تُعد ظاهرة الإرهاب واحدة من أهم القضايا السياسية والأمنية التي تواجه الثعب والتي في التي

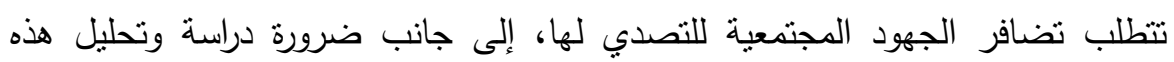
الظاهرة للوقوف على أسبابها، وتداعياتها وسبل مكافحتها.

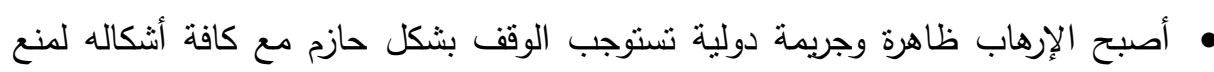
انتشاره على نطاق واسع ومحاصرته أينما ظهر والقضاء عليه.

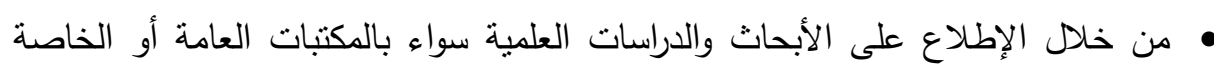

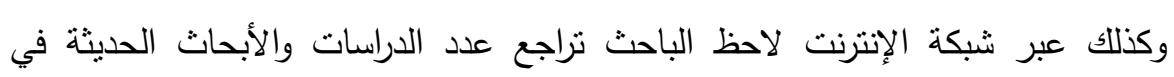

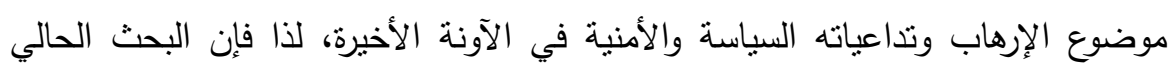

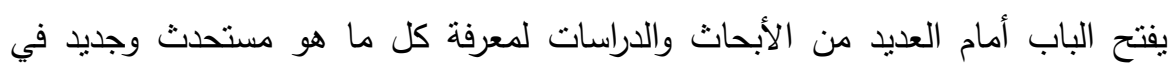
موضوع الآثار الأمنية والسياسية للإرهاب. • من المتوقع أن يسهم البحث الحالي في تقديم المعلومات والحقائق الأمنية والسياسية الهامة التي تصل في نهايتها إلى مجموعة من النتائج والتوصيات التي قد تلفي تفيد المسؤولين

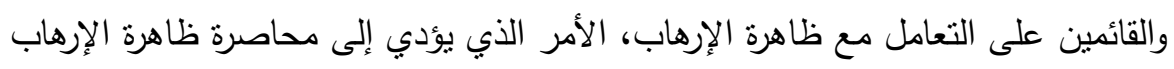
بكل أثنكالها وصورها، ووضعها تحت السيطرة ومن ثمّ الحد من تداعياتها وأثنارها المختلفة. جدول رقم(ب): الخاص بأوجه الأستعادة من الدورات التدريبية

\begin{tabular}{|c|c|c|c|c|}
\hline الترتيب & النسبة & ك & | العبارات & e \\
\hline 1 & $T 0, r$ & $\overline{Y .}$ & إكتساب خبرات جديدة في العمل الزمنى & $\overline{\mathrm{T}}$ \\
\hline 1 & ro,r & r. & إستخدام الآلية اللامة في إدارة المشكلات & ب ب \\
\hline 1 & ro, r & r. & تتمية القدرات البشرية للعاملين في الجهاز & $\rightarrow$ \\
\hline r & $r \varepsilon, 0$ & 19 & تبادل الآراء والأفكار الجديدة في تخفيض تحقيق الآمن & د \\
\hline
\end{tabular}


يتضح من جدول رقم (r) اهمية الأستفادة من الدورات التدريبية واعداد مقومات بشرية

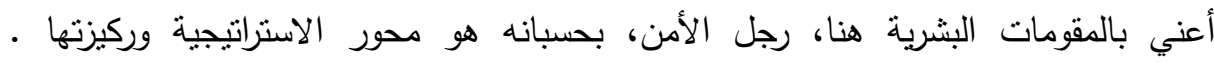

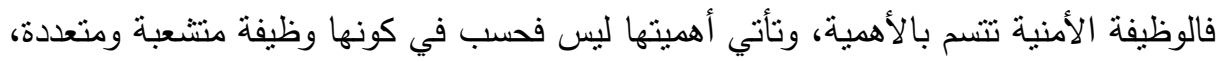

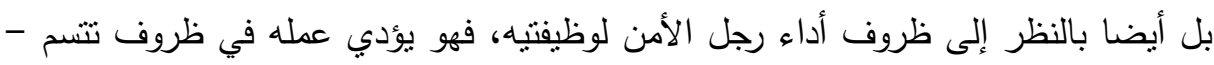
إلى حد ما -بالخطورة

ومن هنا نوجه النظر إلى ضرورة وضع ضوابط ومعايير دقيقة لاختبار رجل الأمن،

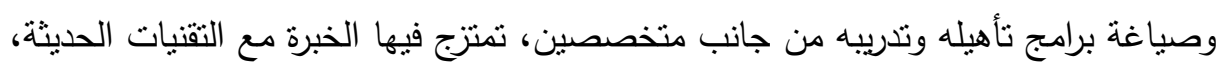

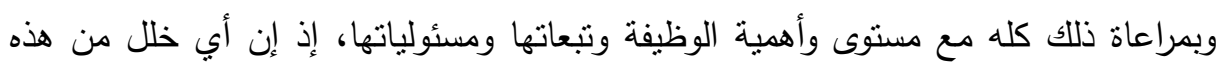
المعادلة في احد جوانبها يؤثر سلبا في الجانب الآخر . وإذا كنا هنا لسنا بصدد الحديث عن تأهيل وتدريب رجل الأمن، بحسبانها وسائل لرفع

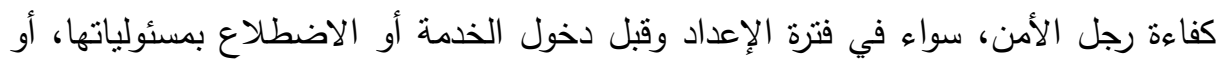
بعد الانخراط في الخدمة بهدف إمداد رجل الأمن بالمعلومات الضرورية التي تحقق تتميته في

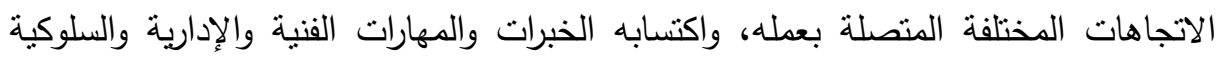
اللازمة لأدائه، إلا إننا نعني هنا بالعنصر البشري المنوط به تتفيذ الاستراتيجية بتبعاتها

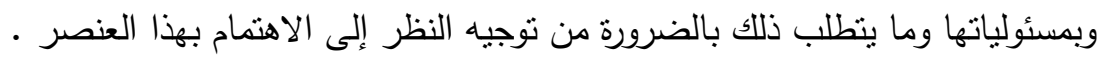

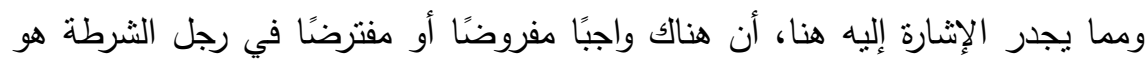

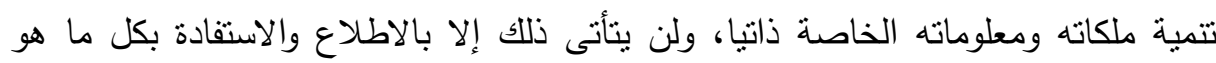
جديد في مجال الأمن سواء بالداخل أو الخارج وذلك بغية رفع مستوى الأداء وفي إعلاء شأن أنان

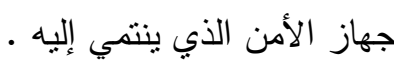
ويأتي بعد ذلك تدريب أفراد جهاز الأمن، والتدريب هنا لا بهدف فحسب إلى إمداد المتدرب بالمعلومات الضرورية التي تحقق تتميته في الاتجاهات المختلفة، المتصلة بعمله،

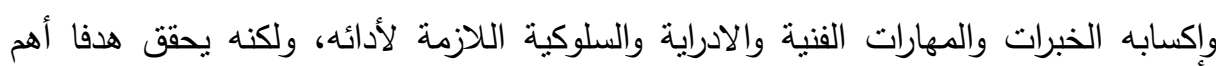

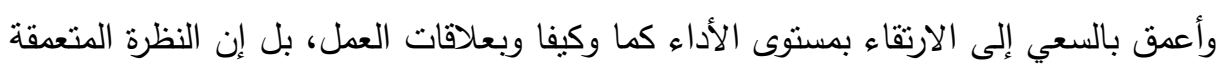
للتدريب تؤكد اهتمامه أيضا بخدمة أهداف العاملين وإثباع حاجاتهم إلى الإحساس بألى بألمن 
والاستقرار وزيادة ثقتهم بأنفسهم وبما يؤدونه من أعمال، وهي عوامل لتتمية الانتماء للأجهزة

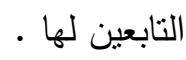
وتقوم فلسفة التدريب على منطق واضح يفترض أن الأعداد والنوعيات المطلوبة من الكفاءات البشرية لممارسة أعمال معينه تتطلب مستوى عالٍ من الكفاءة والمقدرة، كما هو الحال بالنسبة للتخصصات المطلوبة. وفي مجال الأمن، لا يمكن أن تتوفر بالاعتماد على القدرات الطبيعية والتلقائية وحدها

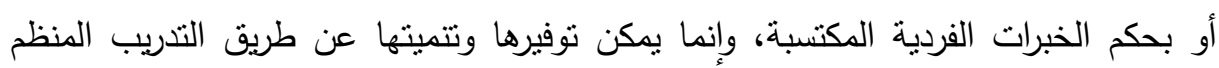

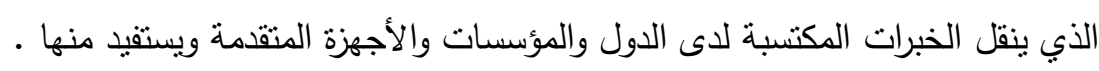

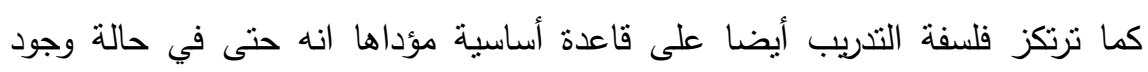

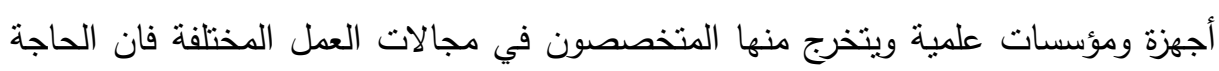
سنظل قائمة إلى استخدام التدريب أيضًا لتوفير الأساليب وفتح آفاق جديدة من المعرفة المنات المهنية

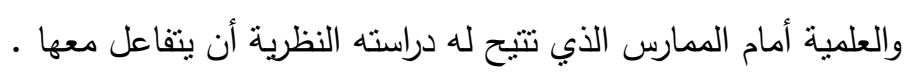

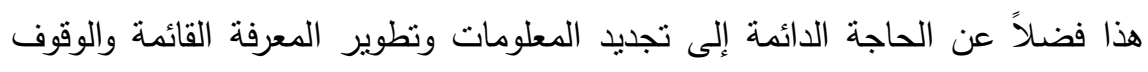

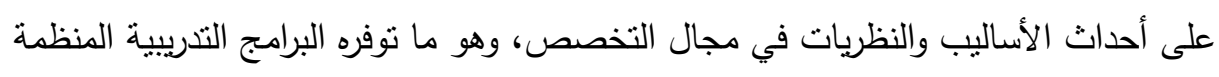

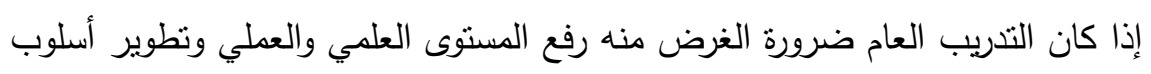

الأداء فالتدريب المتخصص يعمل على تعميق المعلومات التخصصية لعملية محددة، أو مهارة

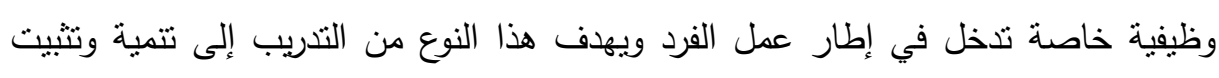

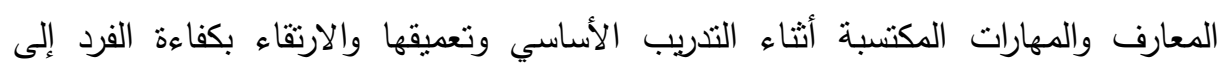

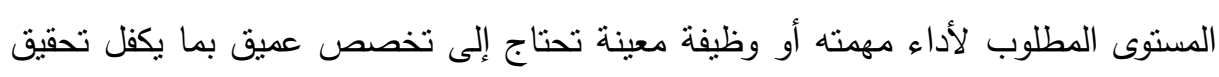
الكفاءة المطلوبة

ومن مجموع ما تقدم يتبين أن اختيار الكوادر الأمنية القادرة على تتفيذ الإستراتيجية

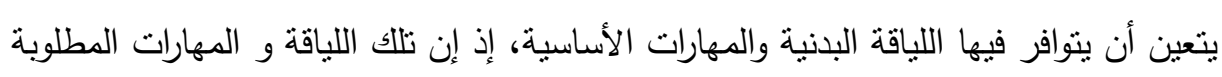

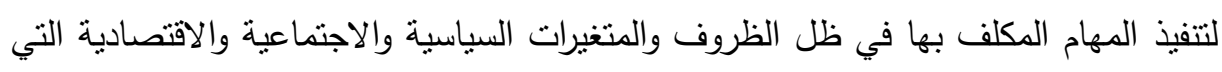
شهدها العالم في الآونة الأخيرة، كما ينبغي أن يتوافر في رجل الأمن مسنوى من الذكاء والقدرات الذهنية التي تمكنه من استيعاب الاستراتيجية التدريبية وأبعادها وغاياتها، إذ إن إن إن

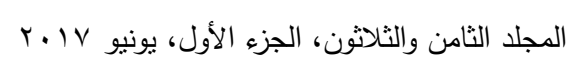


الاستراتيجية في جانب منها نعتمد على الدروس النظرية والتطبيقية المستتدة إلى نظريات علمية أو فلسفية معقدة وفي جانب آخر عملية قائمة على أساس المشاهدة العلمية الجماعية

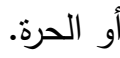

وإذا أخذنا الاعتبارات المنقدمة في الحسبان عند التخطيط للتدريب، فانه سيؤتى ثماره

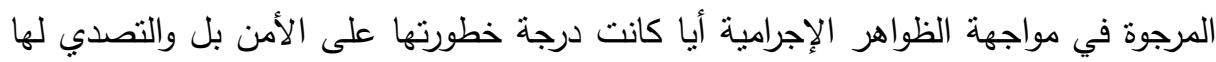

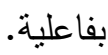
إن القضاء على ظاهرة الإرهاب بمختلف أثنكالها وصورها وأساليبها المتتوعة، أمر

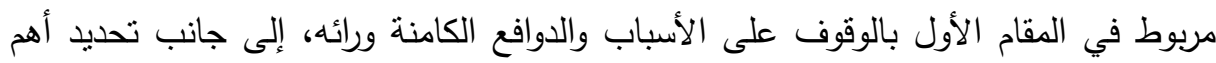

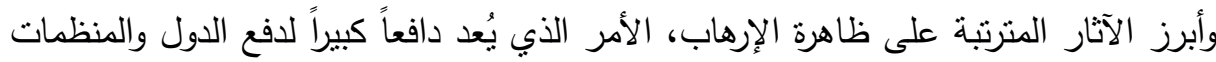

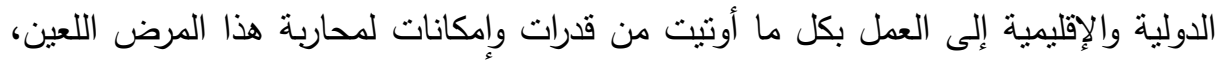
وقد استعرض البحث الحالي الآثار السياسية والأمنية المترتبة على ظاهرة الإرهاب، وكيف أنها

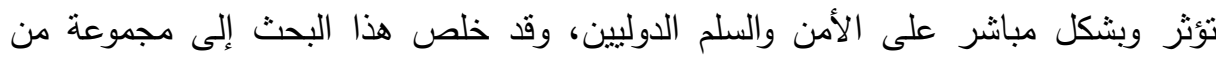

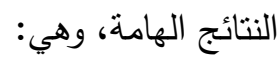
- إن وضع تعريف موحد للإرهاب يمثل أكبر التحديات التي تواجه جهود عملية مكافحة الإرهاب، ويعود ذلك إلى طبيعة الظاهرة الإرهابية، فهو مصطلح ديناميكي (حركي) يختلف نتيجة اختلاف صور الإرهاب واشكاله وأساليبه، كما أن هناك إثكالية هامة في تعريف الإرهاب تتمنل في غياب الحيادية في وصف ظاهرة الإرهاب.

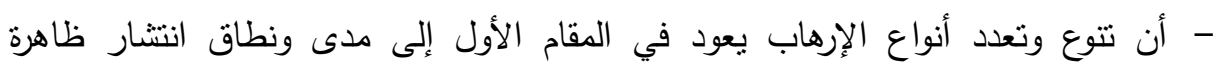

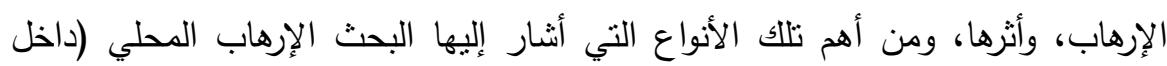

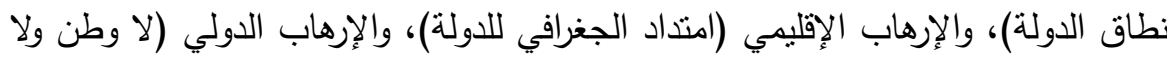
دين)، وأخيرا إرهاب الأفراد أو الجماعات والمنظمات الإني الخاصة.

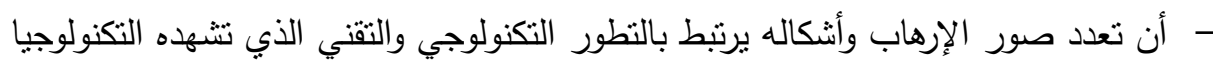
والصناعات الحيوية، فنجد أن هناك الإرهاب الإلكتروني (فيروسات الحاسب الآلكي

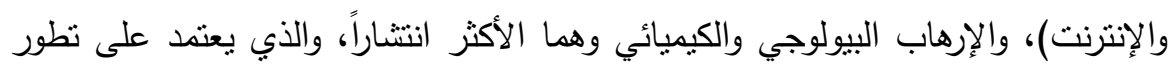


الصناعات البيولوجية والكيميائية سواء داخل القطاعات المدنية أو القطاع العسكري، وأخيرا

$$
\text { الإرهاب النووي وهو قديم عن الصور السابقة. }
$$

- يتخذ الإرهاب أساليب مختلفة للقيام بتحقيق أهدافه بداية من التقجيرات بمختلف أثنكالها،

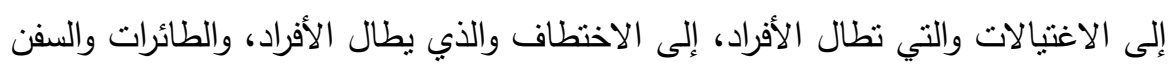
وغيرها، وأخيراً الأعمال التخريبية كقطع السكك الحديدية والجسور وغيرها. - أنثارت نتائج البحث إلى أن مجالات العلاقات الدولية تلعب دوراً هاماً وكبيراً في انتشار

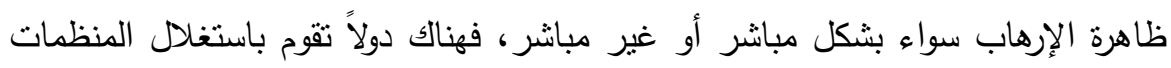
الإرهابية لتحقيق أهدافاً قد بصعب عليها تحقيقها من خلإل الحروب المباشرة، كما أن هناك بعض الدول التي تقوم بتقديم الدعم للمنظمات الإرهابية والثخصيات الإرهابية كحق الثقابه

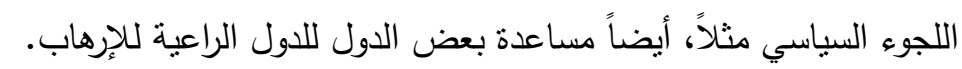

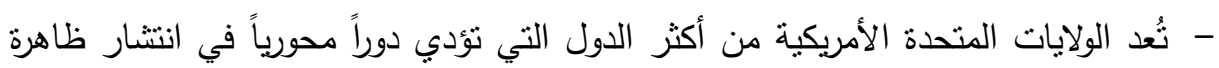

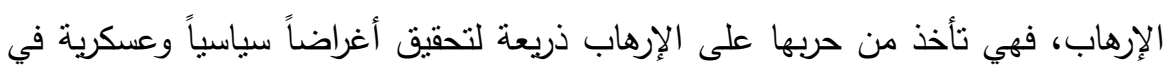
منطقة الثرق الأوسط، إلى جانب فرض سيطرتها على آبار النقط في المنطقة.

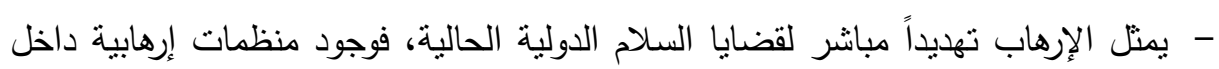

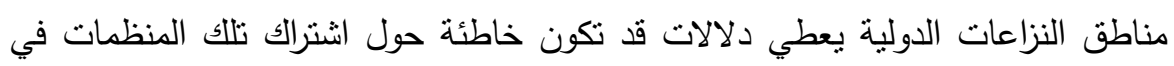

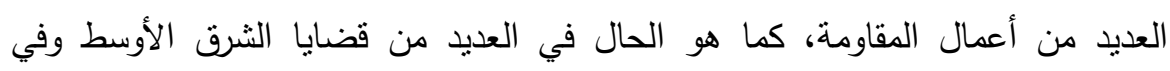
مقدمتها الصراع العربي الإسرائيلي. - من أكثر الآثار السلبية على الحياة السياسة جراء ظاهرة الإرهاب إساءة استعمال امنياز الحصانة الدبلوماسية واستخدمها في تمرير الصفقات المشبوهة كصفقات السلاح والأموال. - - إن محاولة البعض إلصاق تهمة الإرهاب بالإسلام هي محاولة للنيل من سمعة المسلمين،

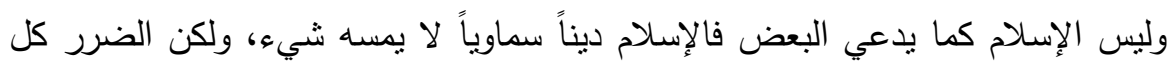
الضرر على المسلمين الذين ألصقت بهم تهمة الإرهاب.

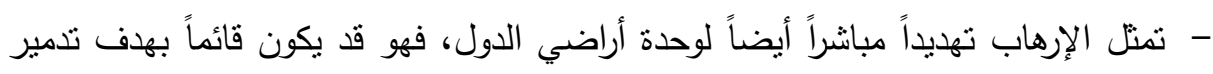

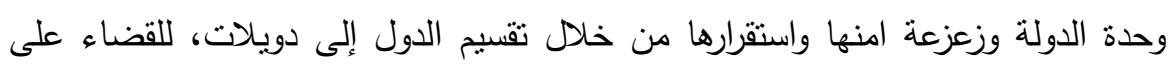

$$
\text { وطنية ووحدة الثعوب. }
$$


- تُعد الثائعات وترويج الأفكار المنطرفة أهم أساليب ووسائل المنظمات الإرهابية، لذا فإن

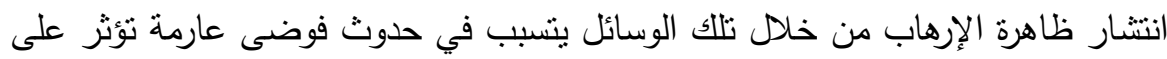

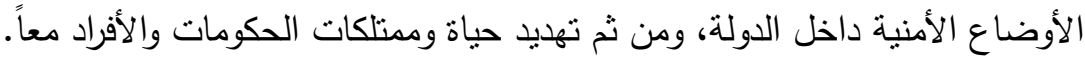
- إن قيام المنظمات الإرهابية والإرهابيين بعمليات التفجيرات المستمرة وفي ظله نل مطاردة عناصر الأمن لهم، يؤدي إلى نتائج سلبية في مقدمتها الفزع والهلع للمواطنين، تراجع

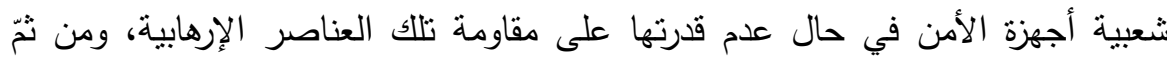
فقدان المواطنين النقة في رجال الأمن، كما تتسب عملية المطاردة إلى فقدان الأرواح من فن الأنس

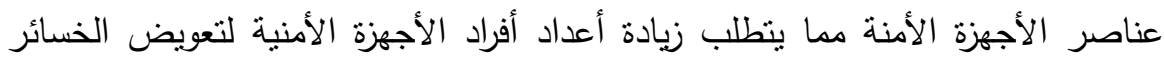
البشرية. - إن استمرار العمليات الإرهابية أمر يتطلب ضرورة قيام الدول والمنظمات الدولية بإصدار تعليمات أمنية جديدة، من شأنها الحد من مخاطر العمليات الإرهابية، وذللك من خلا لإل

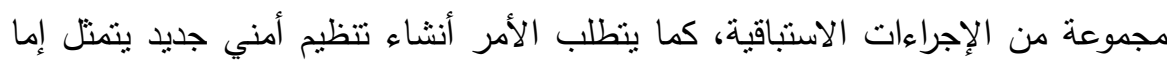

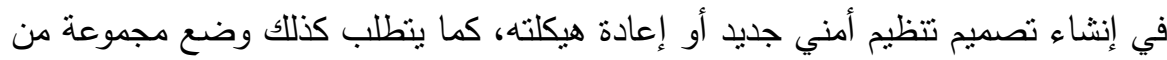
القواعد الأمنية الجديدة تكون أكثر صرامة لمواجهة الأعمال الإرهابية.

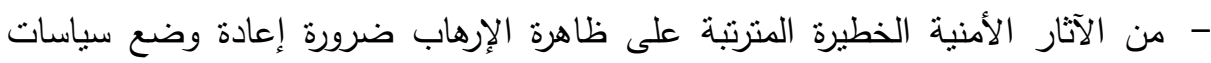
أمنية جديدة لتحكم وضبط الأجهزة الأمنية العامة في مجال مكافحة الإرهاب.

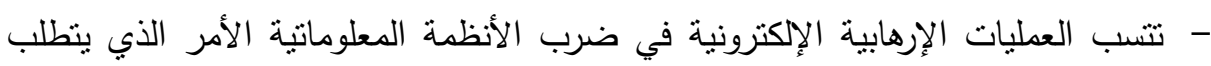
إنشاء قاعدة بيانات مركزية حديثة مع العمل على تبادل المعلومات للمحافظة عليها من الإنه الاختراق والتلف. - تتعكس جريمة الإرهاب على الأوضاع الأمنية من خلال علاقتها بالجريمة المنظمة في

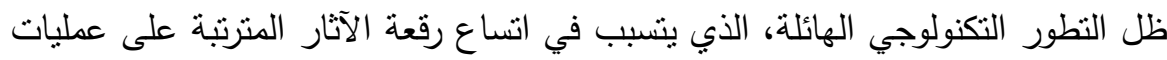

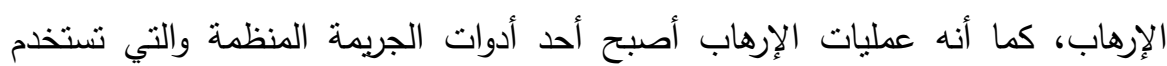
لتحقيق أهداف سواء على مسنوى الأفراد أو على مسنوى الدولة. 


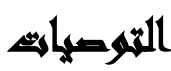

- وضع تعريف محدد وشامل لمفهوم الإرهاب نتبناه كافة الدول والمنظمات الدولية والإقليمية.

- وجوب عقد الأبحاث والدراسات عن الآثار السياسية والأمنية المترتبة على ظاهرة الإرهاب

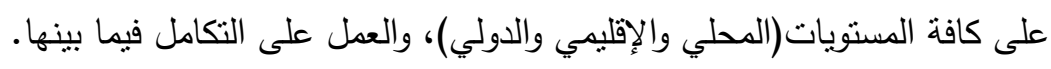

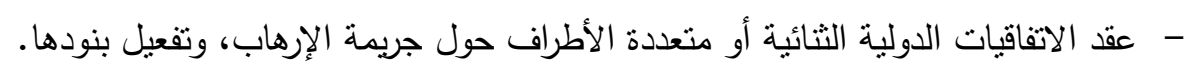

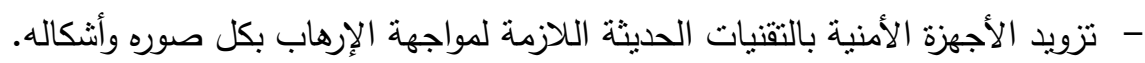
- إنثاء وتطوير الأنظمة الأمنية، بحيث تتواكب مع التطور النوعي في العطليات الإرهابية. - التدريب الدائم والمستمر لأفراد أجهزة الأمنين العالمين في مجال مكافحة الإرهاب.

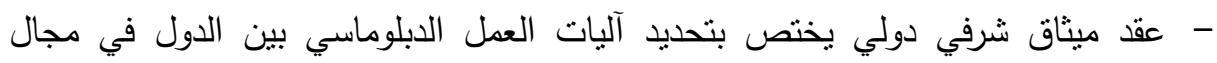

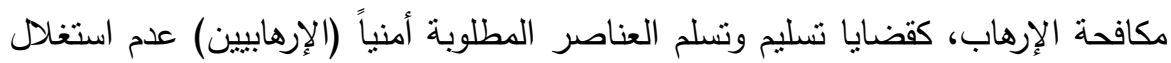
القنوات الدبلوماسية في تحقيق أهداف المنظمات الإرهابية.

- وضع استراتيجية أمنية بالتعاون بين الأنظمة الأمنية المحلية والإقليمية والدولية لتضيق الإنيق الخناق على المنظمات الإرهابية وتجفيف مصادر تمويلها.

إستراتيجية مواجهة المشكلات البيئية والإجتماعية الناتجة عن العنائية العمليات الإرهابية:

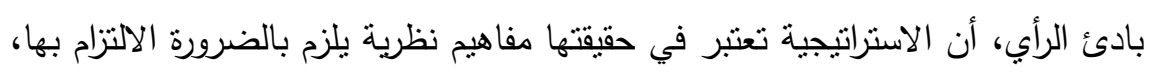

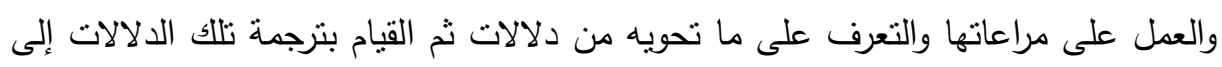
معطيات في ضوء المطلوب من مهام والمتاح من إمكانات.

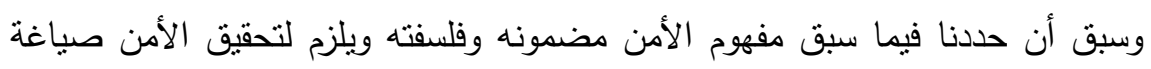
استراتيجية نستلهم الدلالات السابقة، ومراعاة المتاح من الإمكانات سواء المادية أو التتظيمية

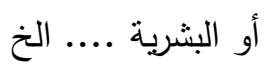
وفي ضوء ما تقام، فان مقومات الإستراتيجية لا تخرج في مجملها عن: - مقومات بشرية :إعداد وتدريب على اسس المواجهة والتتبؤه بشكال الجريمة المنظمة فئنة - مقومات مادية: استخدم التكنولوجيا الحديثة 
- مقومات تنظيمية ومشاركو مجتماعية : يعد هذا العنصر الاهم في الاستراتيجة وهوه عمل

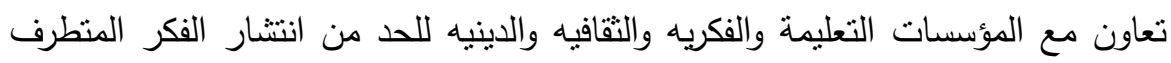
والسعى على تحقيق الانتماء. - مقومات تثريعية: تحديث التشرعات المتعلقة بجرمية المنظمة على اسس نواكب تقدم تلاهك العلام في تعدد اشكالها.

\section{المراميع}

أ. وياروشفسكي بتروفسكي (797 (1): معجم علم النفس المعاصر ، ترجمة: حمدي عبد الجواد وعبد السلام رضوان، دار العالم الجديد، القاهرة

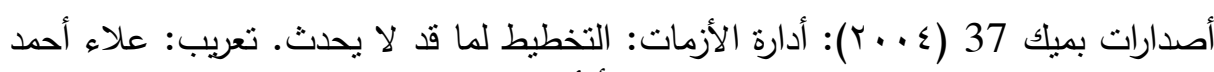
صلاح، مركز الخبرات المعنية بألأدارة، القاهرة

صفوت فرج(ب999): قضية الإرهاب: محاولة للفهم السيكولوجي. دراسات نفسية. ؛ (r). $\varepsilon Y \wedge-\varepsilon) T$

$$
\text { عبد الأله البلداوي(T + . r): كيفية ادارة الأزمات }
$$

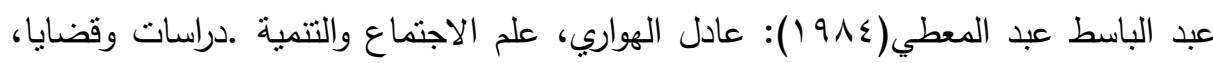

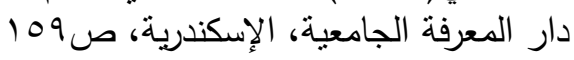

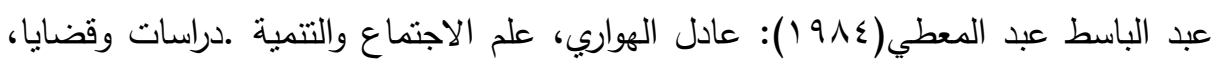

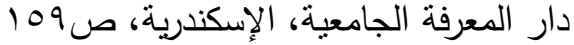

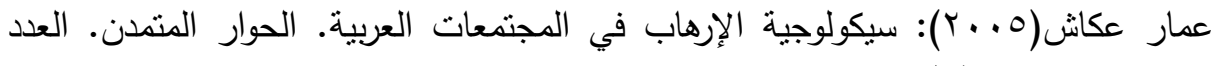
$1 \leq .0$

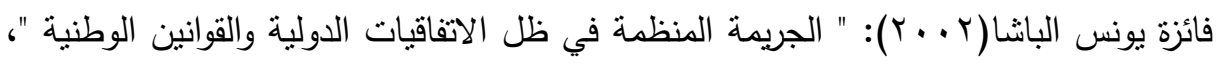
دار النهضة العربية، القاهرة

فرح لفتنة عامر الحداد(؟99 (1):ادارة الأزمات في المنظمات العراقية: دراسة ميدأنية لعينة في

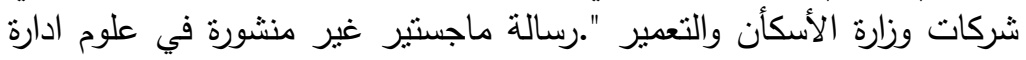

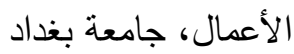


ماجد إبراهيم علي(ء . . rم): "قانون العلاقات الدولية - دراسة في إطار القانون الدولي

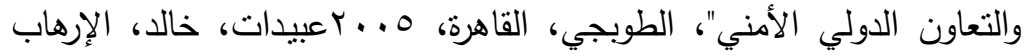
بسيطر على العالم، دائرة المطبوعات والنشر ، عمان.

محمد بدوي( · . [rم): النظرية السياسية: المعرفة العامة السياسية، المكتب المصري الحديث،

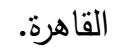

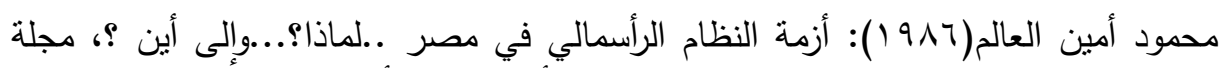

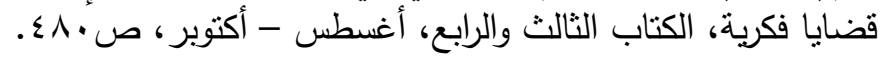

$$
\text { منير البعلبكي(·191 ) ): المورد القريب، دار العلم للملايين، لبنان }
$$

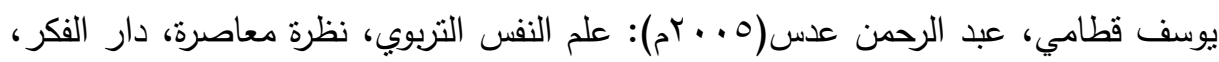
عمان.

Bryan 'Valerie Louise ،University of Kentucky individual and community level socie Economic factors and Drug court outcomes Analysis and implications 'Proguest 'UMI ، Dussertations publishing ،2005،3198302.

Whithney,C. and Julianne, S., Americans and Europeans Agree Terrorism is Top Threat. www. worldviews. org (19/9/2006), 2002 .

The Center for Strategic Studies at the University of Jordan, Arab Attitudes on US, UK, France, Terrorism. www. justworldnews. org. (10/12/2006), 2005. Hudson،

Albert, Bandura, (1990), Mechanisms of moral disengament, Cambrige university press, Cambrige

Anonymous, (1982), Terrorism: TvI Journal 3, pp. 3 -6

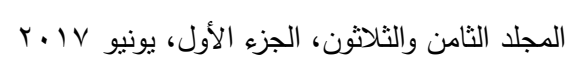


معهذ الدراسات والبحوث البيئية - جامعة عين شمس البئ

\title{
ALMSTKHALSASTRATEJAH ADDRESS \\ ENVIRONMENTAL AND SOCIAL PROBLEMS \\ OLNTEGH FOR TERRORIST OPERATIONS \\ SISOLOGIH STUDY
}

\author{
Abdel Azim, S. S. ${ }^{(1)}$; Hani, A. F. ${ }^{(2)}$ Hawash, G. A. ${ }^{(3)}$ \\ and Awad, Kh. M. I. ${ }^{(4)}$
}

1) Institute for Environmental Studies and Research, Ain Shams University.2) Faculty of Arts, Ain Shams University.3) Nasser Higher Military Academy 4) Ministry of The Interior

\begin{abstract}
Problem of the studyThe spread of terrorist operations in many countries, this picture confirms that there is a problem threatening the community but the entire world, terrorism, organized crime, which the problem is complicated, and contributed to the adoption of the illicit drug trade Tejarat weapon is a form of organized crime, as a result of political and economic conditions experienced by most countries, especially developing countries, these circumstances led to the inability of states to keep pace with this development in organized crime, modern and sophisticated style systematic followed by criminal organizations in achieving their goals, also contributed to the spread of this phenomenon are other factors branched workers to intensify efforts and cooperation at all levels, as appropriate, in order to improve security in the preparation and issuance of identification cards and travel documents and to prevent and detect manipulated or used a false, recognizing at the same time that States may require assistance to do so. In this regard, the International Criminal Police Organization call for the strengthening data on stolen and lost travel documents database, and we will seek to take full advantage of this
\end{abstract}

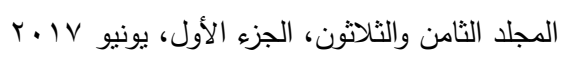


tool, as appropriate, in particular through the exchange of information relating to this matter; the political and economic presidents.

And terrorism is no longer just a simple phenomenon appear and then disappear. It has become a painful reality experienced by individuals, institutions and nations. And it became an individual suffering from a deterioration in the psychological structure, whether it be a spectator or a follower or a victim. So states recruit energies and capabilities to reduce this phenomenon and work to uproot man's humanity to preserve and maintain their dignity. Terrorism constitutes one of the important themes and contemporary which has great interest in the political, military, economic, social, and educational and psychological. Proof of this is what we read and we hear and see a day of events in various media so that terrorism has become a reality we live in and live with it in our daily lives.

They have multiplied the means of terrorism and terrorists has proven their ability to use all the means of modern science and its applications in ways to reach their goals. And characterized dangerous terrorist operations, impact and this was due primarily dense coverage by the different media with consequent hype and excitement. In addition, information and communication technologies contribute to the rapid spread of news of terrorists, and this may help to exacerbate international terrorism. 